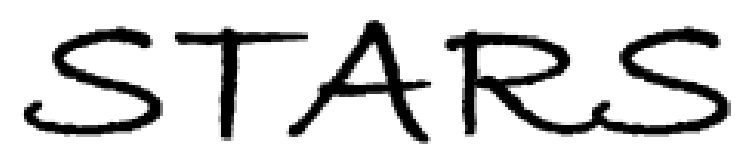

University of Central Florida

STARS

\title{
Synthesis, Processing And Characterization Of Nanocrystalline Titanium Dioxide
}

Shipeng Qiu

University of Central Florida

Part of the Materials Science and Engineering Commons

Find similar works at: https://stars.library.ucf.edu/etd

University of Central Florida Libraries http://library.ucf.edu

This Masters Thesis (Open Access) is brought to you for free and open access by STARS. It has been accepted for inclusion in Electronic Theses and Dissertations, 2004-2019 by an authorized administrator of STARS. For more information, please contact STARS@ucf.edu.

\section{STARS Citation}

Qiu, Shipeng, "Synthesis, Processing And Characterization Of Nanocrystalline Titanium Dioxide" (2006). Electronic Theses and Dissertations, 2004-2019. 913.

https://stars.library.ucf.edu/etd/913

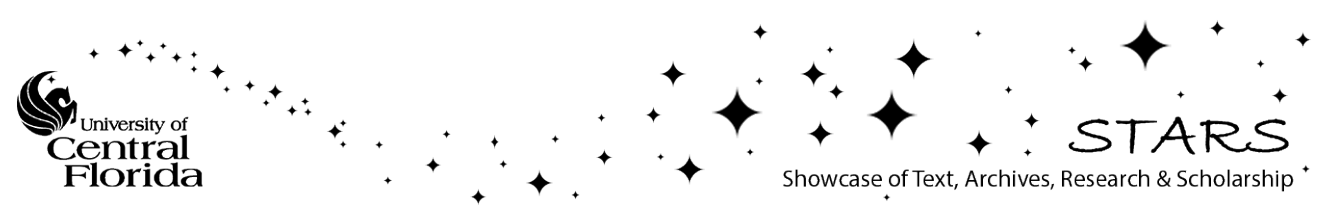




\title{
SYNTHESIS, PROCESSING AND CHARACTERIZATION OF NANOCRYSTALLINE
} TITANIUM DIOXIDE

by

\begin{abstract}
SHIPENG QIU
B.S. Tianjin University, 2000

M.S. Tianjin University, 2003
\end{abstract}

\author{
A thesis submitted in partial fulfillment of the requirements \\ for the degree of Master of Science \\ in the Department of Mechanical, Materials and Aerospace Engineering \\ in the College of Engineering and Computer Science \\ at the University of Central Florida \\ Orlando, Florida
}


C 2006 Shipeng Qiu 


\section{ABSTRACT}

Titanium dioxide $\left(\mathrm{TiO}_{2}\right)$, one of the basic ceramic materials, has found a variety of applications in industry and in our daily life. It has been shown that particle size reduction in this system, especially to nano regime, has the great potential to offer remarkable improvement in physical, mechanical, optical, biological and electrical properties. This thesis reports on the synthesis and characterization of the nanocrystalline $\mathrm{TiO}_{2}$ ceramic in details.

The study selected a simple sol-gel synthesis process, which can be easily controlled and reproduced. Titanium tetraisopropoxide, isopropanol and deionized water were used as starting materials. By careful control of relative proportion of the precursor materials, the $\mathrm{pH}$ and peptization time, $\mathrm{TiO}_{2}$ nanopowder was obtained after calcination at $400^{\circ} \mathrm{C}$. The powder was analyzed for its phases using X-ray powder diffraction (XRD) technique. Crystallite size, powder morphology and lattice fringes were determined using high-resolution transmission electron microscopy (HR-TEM). Differential scanning calorimetry (DSC) and thermal gravimetric analysis (TGA) were used to study the thermal properties. As-synthesized powder was uniaxially compacted and sintered at elevated temperature of $1100-1600^{\circ} \mathrm{C}$ to investigate the effects of sintering on nano powder particles, densification behavior, phase evolution and mechanical properties. Microstructure evolution as a function of sintering temperature was studied by scanning electron microscopy (SEM)

The results showed that $400^{\circ} \mathrm{C}$ was an optimum calcination temperature for the assynthesized $\mathrm{TiO}_{2}$ powder. It was high enough to achieve crystallization, and at the same time, helped minimize the thermal growth of the crystallites and maintain nanoscale features in the 
calcined powder. After calcination at $400^{\circ} \mathrm{C}(3 \mathrm{~h}), \mathrm{XRD}$ results showed that the synthesized nano- $\mathrm{TiO}_{2}$ powder was mainly in single anatase phase. Crystallite size was first calculated through XRD, then confirmed by HR-TEM, and found to be around $5 \sim 10 \mathrm{~nm}$. The lattice parameters of the nano- $\mathrm{TiO}_{2}$ powder corresponding to this calcination temperature were calculated as $\mathrm{a}=\mathrm{b}=0.3853 \mathrm{~nm}, \mathrm{c}=0.9581 \mathrm{~nm}, \alpha=\beta=\gamma=90^{\circ}$ through a Rietveld refinement technique, which were quite reasonable when comparing with the literature values. Considerable amount of rutile phase had already formed at $600^{\circ} \mathrm{C}$, and the phase transformation from anatase to rutile fully completed at $800^{\circ} \mathrm{C}$. The above rutilization process was clearly recorded from XRD data, and was in good corresponding to the DSC-TGA result, in which the broad exothermic peak continued until around $800^{\circ} \mathrm{C}$. Results of the sintered $\mathrm{TiO}_{2}$ ceramics $\left(1100^{\circ} \mathrm{C}\right.$ $1600^{\circ} \mathrm{C}$ ) showed that, the densification process continued with the increase in sintering temperature and the highest geometric bulk sintered density of $3.75 \mathrm{~g} / \mathrm{cm}^{3}$ was achieved at $1600^{\circ} \mathrm{C}$. The apparent porosity significantly decreased from $18.5 \%$ to $7.0 \%$ in this temperature range, the trend of which can be also clearly observed in SEM micrographs. The hardness of the $\mathrm{TiO}_{2}$ ceramics increased with the increase in sintering temperature and the maximum hardness of $471.8 \pm 30.3 \mathrm{HV}$ was obtained at $1600^{\circ} \mathrm{C}$. Compression strength increased until $1500^{\circ} \mathrm{C}$ and the maximum value of $364.1 \pm 10.7 \mathrm{MPa}$ was achieved; after which a gradual decrease was observed. While sintering at ambient atmosphere in the temperature range of $1100^{\circ} \mathrm{C}-1600^{\circ} \mathrm{C}$ helped to improve the densification, the grain size also increased. As a result, though the sintered density at $1600^{\circ} \mathrm{C}$ was the highest, large and irregular-shaped grains formed at this temperature would lead to the decrease in the compression strength. 
Dedicated to my wife, parents and friends 


\section{ACKNOWLEDGMENTS}

I would like to express my deep gratitude to my advisor Dr. Samar J. Kalita. His technical guidance, life counsel, continuous support, encouragement help and patience have always been highly appreciated. I would also like to express my sincere appreciation to Dr. Linan An and Dr. Christine Klemenz for being the committee members and evaluating my thesis. My thanks also extend to Department of Mechanical Materials and Aerospace Engineering (MMAE), Advanced Materials Processing and Analysis Center (AMPAC) and UCF for their financial and experimental support.

Moreover, I would like to thank my labmates and friends, Mr. Himesh Bhatt, Mr. Vikas Somani and Ms. Abhilasha Bardhwaj, who provided useful hints and ideas throughout my research.

Finally, sincere thanks go to my lovely wife and my dear parents, for their everlasting love, support, encouragement and understanding. 


\section{TABLE OF CONTENTS}

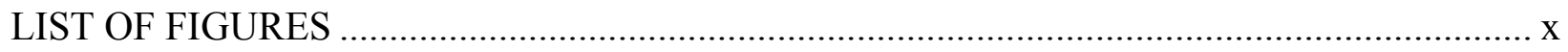

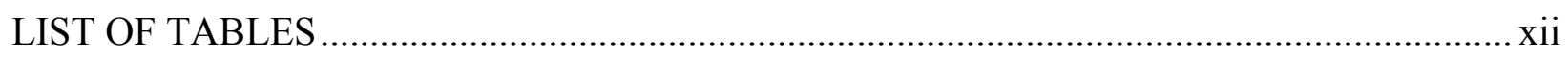

LIST OF ACRONYMS/ABBREVIATIONS ................................................................. xiii

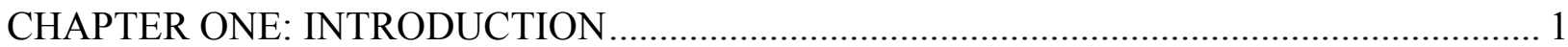

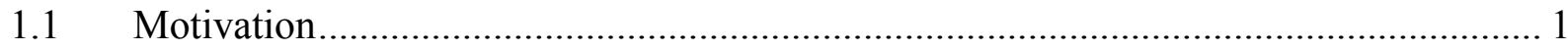

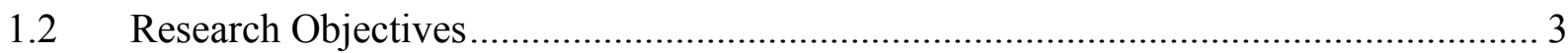

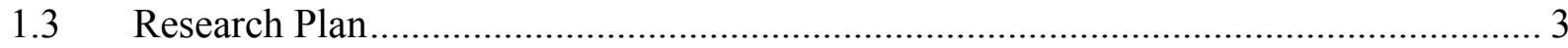

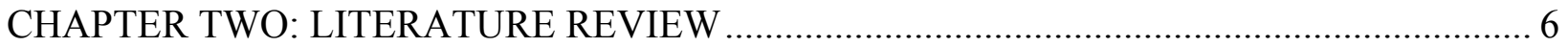

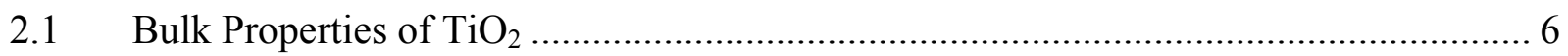

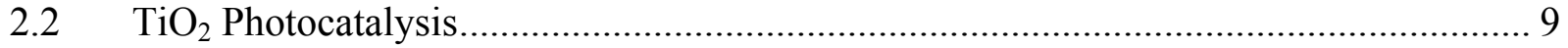

2.3 Photo-induced Superhydrophilicity .................................................................. 12

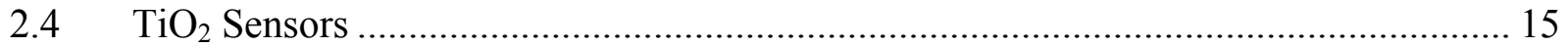

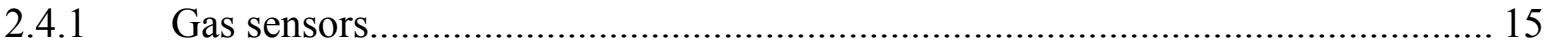

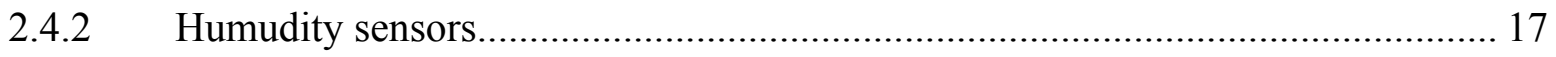

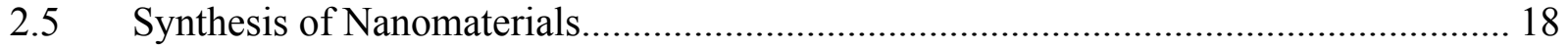

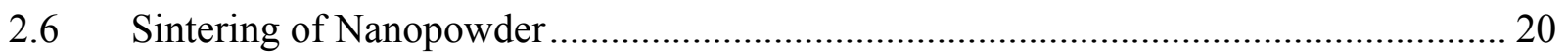

2.7 Mechanical Behavior of Nanocrystalline Materials ............................................... 23

2.8 Rietveld Refinement Technique ........................................................................ 25

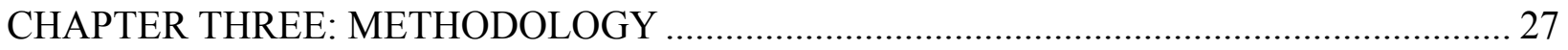

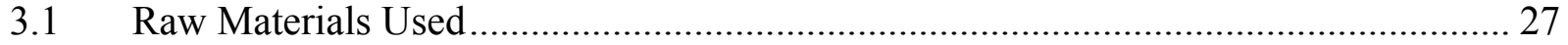




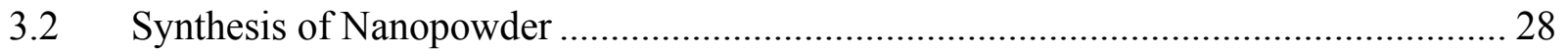

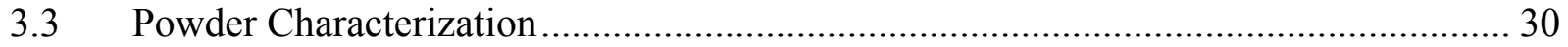

3.3.1 Characterization of as-received $\mathrm{TiO}_{2}$ (anatase) powder …………………........ 30

3.3.2 Characterization of synthesized $\mathrm{TiO}_{2}$ nano-powder ........................................ 30

3.3.2.1 Differential scanning calorimetry / thermal gravimetric analysis..................... 30

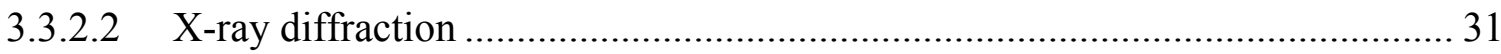

3.3.2.3 High-resolution transmission electron microscopy ………........................... 32

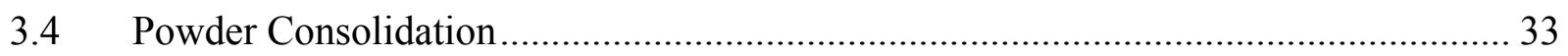

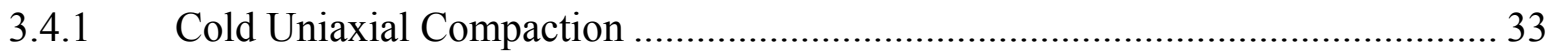

3.4.2 Sintering of Compacted Structures ....................................................................... 34

3.5 Characterization of the Sintered Structures ………………...................................... 34

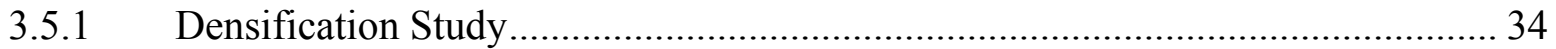

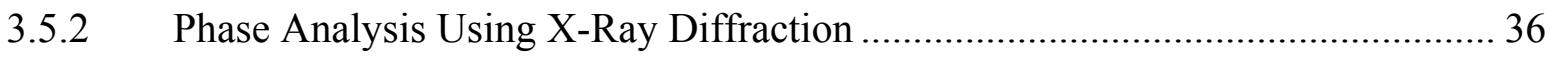

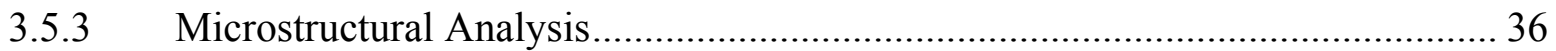

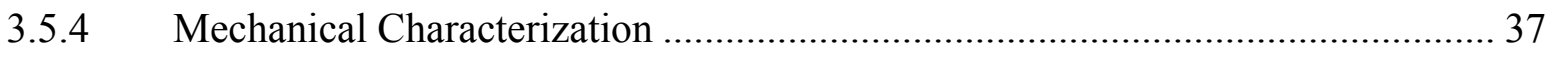

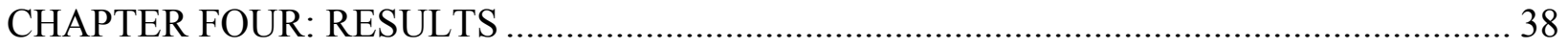

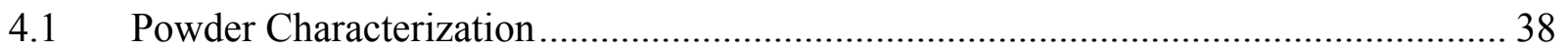

4.1.1 Differential Scanning Calorimetry / Thermal Gravimetric Analysis..................... 38

4.1.2 Phase Analysis and Crystallite Size Determination................................................ 39

4.1.3 High-resolution Transmission Electron Microscopy ………………………........ 40

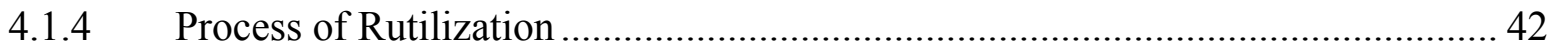

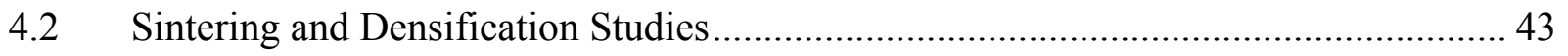


4.2.1 Density and Porosity Development ..................................................... 43

4.2.2 Phase Transformation/Evolution Analysis ............................................... 46

4.2.3 Microstructural Analysis.................................................................... 48

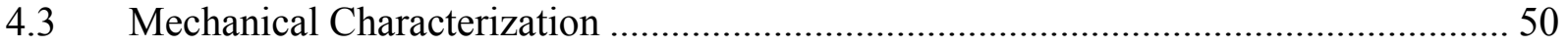

4.3.1 Vickers Hardness Testing ...................................................................... 50

4.3.2 Compression Testing ........................................................................... 51

4.4 Rietveld Refinement of X-ray Diffraction Data ............................................... 52

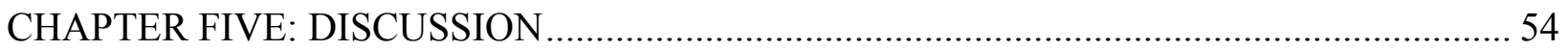

5.1 Phase Evolution and Transformation in Calcined Nanocrystalline $\mathrm{TiO}_{2}$ Powders ....... 54

5.2 Sintering and Densification of $\mathrm{TiO}_{2}$ Ceramics ...................................................... 58

5.3 Mechanical Properties of Sintered $\mathrm{TiO}_{2}$ Ceramics ................................................ 59

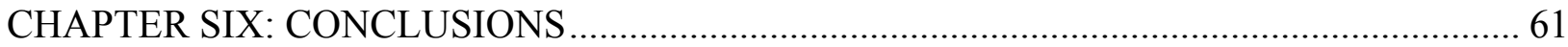

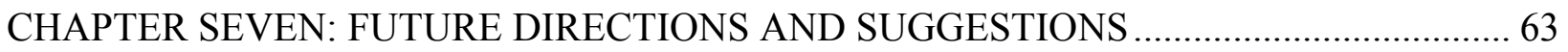

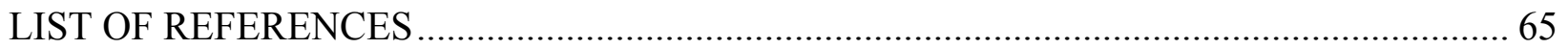




\section{LIST OF FIGURES}

Figure 1. Flowchart of the research plan in this study................................................... 5

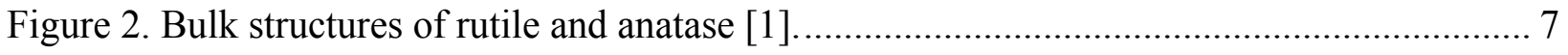

Figure 3. Phase diagram of the Ti-O system [27]. The region $\mathrm{Ti}_{2} \mathrm{O}_{3}-\mathrm{TiO}_{2}$ contains $\mathrm{Ti}_{2} \mathrm{O}_{3}, \mathrm{Ti}_{3} \mathrm{O}_{5}$, seven discrete phases of the homologous series $\mathrm{Ti}_{\mathrm{n}} \mathrm{O}_{2 \mathrm{n}-1}$ (Magneli phases) and $\mathrm{TiO}_{2} \ldots \ldots \ldots . . . .8$

Figure 4. Number of publications regarding $\mathrm{TiO}_{2}$-photocatalysis per year [4] ...................... 10

Figure 5. Field test of stain-resistant exterior tiles in polluted urban air [46] ......................... 14

Figure 6. Thick film gas sensors (Adapted from CAOS Inc.) ............................................. 16

Figure 7. (a) Atomic structure of a nanostructured material developed by computational modeling. The black atoms are atoms the sites of which deviate by more than $10 \%$ from the corresponding lattice sit. (b) Effect of grain size on calculated volume fractions of intercrystal regions and triple junctions, assuming grain boundary width of $1 \mathrm{~nm}$ [59]..... 21

Figure 8. Rietveld refinement of diffraction pattern corresponding to nickel powder [75] ........ 26

Figure 9. Chemical structure of titanium isopropoxide ....................................................... 28

Figure 10. Flow chart showing preparation of nano- $\mathrm{TiO}_{2}$ powders through a Sol-Gel process... 29

Figure 11. DSC-TGA traces of the as-synthesized $\mathrm{TiO}_{2}$ powders measured at a heating rate of

$6^{\circ} \mathrm{C} / \mathrm{min}$ in air. 38

Figure 12. Comparison of XRD patterns of commercial $\mathrm{TiO}_{2}$ and nanocrystalline $\mathrm{TiO}_{2}$ powders calcined at $400^{\circ} \mathrm{C}$ for $3 \mathrm{~h}$. Other unlabeled peaks observed in commercial $\mathrm{TiO}_{2}$ are due to the existing impurities, such as $\mathrm{Mg}$ and $\mathrm{Ca}$. 
Figure 13. High-resolution TEM image of as-processed nano- $\mathrm{TiO}_{2}$ powder prepared by a Sol-Gel process and calcined at $400^{\circ} \mathrm{C}$ for $3 \mathrm{~h}$

Figure 14. XRD patterns of nanocrystalline $\mathrm{TiO}_{2}$ powders calcined at $400^{\circ} \mathrm{C}, 600^{\circ} \mathrm{C}$ and $800^{\circ} \mathrm{C}$

for $3 \mathrm{~h}$, respectively

Figure 15. A photograph taken for different $\mathrm{TiO}_{2}$ samples, showing the shape changes after sintering

Figure 16. Comparison of sintered density of $\mathrm{TiO}_{2}$ ceramics, consolidated from commercial and synthesized powders, sintered at different temperatures for $3 \mathrm{~h}$ at ambient atmosphere.

Figure 17. Sintered density and porosity of $\mathrm{TiO}_{2}$ ceramics as a function of sintering temperature.

Figure 18. XRD patterns of $\mathrm{TiO}_{2}$ ceramics sintered at in the range of $1200-1600^{\circ} \mathrm{C}$ for $3 \mathrm{~h} . \ldots \ldots .47$

Figure 19. SEM micrographs of $\mathrm{TiO}_{2}$ ceramics sintered at (a) and (b) $1300^{\circ} \mathrm{C}$; (c), (d) and (g)

$1400^{\circ} \mathrm{C}$, (e) and (f) $1600^{\circ} \mathrm{C}$ for $3 \mathrm{~h}$ at ambient atmosphere.

Figure 20. Variation of Vickers hardness and compression strength of $\mathrm{TiO}_{2}$ ceramics as a function of sintering temperature. 51

Figure 21. A typical load-displacement curve of $\mathrm{TiO}_{2}$ ceramics sintered at $1500^{\circ} \mathrm{C}$ 52

Figure 22. (a) Rietveld refinement results of the nano- $\mathrm{TiO}_{2}$ powder calcined at $400^{\circ} \mathrm{C}$ for $3 \mathrm{~h} \mathrm{(b)}$ The dialogue box showed the reduced $\mathrm{CHI} * * 2$ value was 1.427 and the convergence was achieved 53

Figure 23. Rutile percentage and crystallite size determined by XRD for the nanocrystalline $\mathrm{TiO}_{2}$ powders after calcination at $400^{\circ} \mathrm{C}, 600^{\circ} \mathrm{C}$ and $800^{\circ} \mathrm{C}$ for $3 \mathrm{~h}$. 56 


\section{LIST OF TABLES}

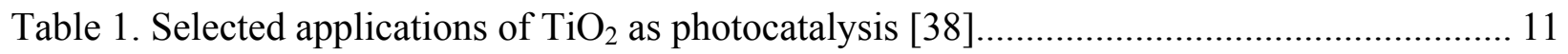

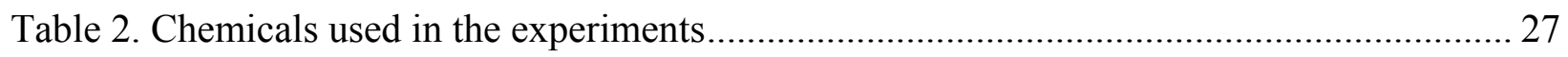

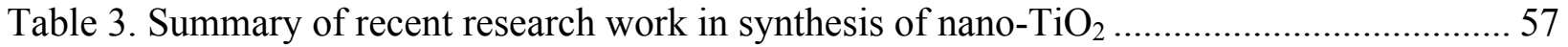




\section{LIST OF ACRONYMS/ABBREVIATIONS}

DSC

TGA

XRD

SEM

TEM

HR-TEM

$\mathrm{TiO}_{2}$

TTIP
Differential Scanning Calorimetry

Thermal Gravimetric Analysis

X-ray Diffraction

Scanning Electron Microscopy

Transmission Electron Microscopy

High Resolution Transmission Electron Microscopy

Titanium Dioxide

Titanium Tetraisopropoxide 


\section{CHAPTER ONE: INTRODUCTION}

\subsection{Motivation}

Titanium dioxide $\left(\mathrm{TiO}_{2}\right)$ ceramic is used in a variety of applications in industry and in our daily life. It can be used as photocatalyst, gas sensor, white pigment (e.g., in paints and cosmetic products), corrosion-protective coating, optical coating, spacer material in magnetic spin-value systems and in solar cells for the production of hydrogen and electric energy [1-4]. It has proved to be biocompatible and is responsible for improved biological performance of Ti-based metallic implants [5]. $\mathrm{TiO}_{2}$ has also been used as a gate insulator for the new generation MOSFETS [6]. In most of the above applications, the particle-size of $\mathrm{TiO}_{2}$ powder used in the fabrication of devices or components is an important consideration, which plays a dominant role in determining the properties and performance of the final products. Some researches have been done to reduce the powder particle-size of $\mathrm{TiO}_{2}$ ceramics, particularly in the nano regime to achieve better properties [7-9]. It has been shown that nanocrystalline ceramics have the potential to offer remarkable improvement in mechanical, optical and electrical properties, by virtue of their high surface area to volume ratio [10].

A number of methods have been developed and used to synthesize nanoscale $\mathrm{TiO}_{2}$ powder, which include chemical vapor deposition (CVD) [11-13], oxidation of titanium tetrachloride $[14,15]$, thermal decomposition and sol-gel technique via hydrolysis of titanium alkoxides [16]. Among these methods, the sol-gel process offers unique advantages such as ease of synthesis, better control over stoichiometric composition, better homogeneity and production of high purity powder [4, 17-20]. Processing conditions, such as chemical concentration, the $\mathrm{pH}$, 
peptization time, calcinations time and temperature have a great influence on the particle size and phase purity of the final powder. Yu et al. synthesized photoactive nano-sized $\mathrm{TiO}_{2}$ with anatase and brookite phase by hydrolysis of titanium tetraisopropoxide (TTIP) in pure water and $\mathrm{EtOH} / \mathrm{H}_{2} \mathrm{O}$ solution under ultrasonic irradiation [21]. They could synthesize powder with average particle-diameter of $22.1 \mathrm{~nm}$. Tang et al. prepared nano rutile $\mathrm{TiO}_{2}$ powder in acidic solution, which had average particle diameter of $50 \mathrm{~nm}$ [19]. It is believed that with decreasing particlesize, the properties of $\mathrm{TiO}_{2}$ ceramics could be increased significantly. In this research, we attempted to reduce powder-particle size of nano $\mathrm{TiO}_{2}$ below $20 \mathrm{~nm}$ through a simple and easily controlled sol-gel process.

One of the fundamental problems of $\mathrm{TiO}_{2}$ ceramic is its poor mechanical properties, which restrict its use in structural applications. Few researches have been done to investigate its mechanical properties. However, with increased interest in mechanical behavior of $\mathrm{TiO}_{2}$ coatings and films, there evolves a need to investigate and enhance its mechanical properties for its relevant applications in gas sensors, as wear resistant materials, or as bioceramic for possible bone graft applications in hard tissue engineering $[22,23]$. In all cases, the mechanical properties of the materials have direct relevance to their good performance in service [24]. For example, the knowledge of the Young's modulus (E), hardness (H) and yield strength (YS) of a film is of particular interest for applications as wear resistant materials. The improvement in mechanical properties will also help to prevent film from cracking, due to drying stresses caused by solvent evaporation and shrinkage. Particle-size reduction is one of the most effective methods to improve the mechanical property of the materials [10]. 


\section{$1.2 \quad$ Research Objectives}

Research objectives of my M.S. thesis project were:

- Synthesis of nanocrystalline $\mathrm{TiO}_{2}$ powder through sol-gel process

- Understanding the thermal properties of the synthesized amorphous powder

- Studying the phase evolution of the synthesized $\mathrm{TiO}_{2}$ powder as a function of temperature

- Characterization of the morphology and particle-size of the synthesized $\mathrm{TiO}_{2}$ powder

- Densification studies of the sintered specimens

- Characterization of mechanical properties of the sintered specimens

- Understanding the correlation between microstructure evolution and mechanical properties changes

\subsection{Research Plan}

In order to achieve the main objectives above, the following studies were carried out.

- Understanding the effects of precursor chemical constituents, their relative proportion, the $\mathrm{pH}$ and peptization time on the final synthesized $\mathrm{TiO}_{2}$ powder

- The thermal properties of the synthesized amorphous powder were studied using Differential Scanning Calorimetry / Thermal Gravimetric Analysis (DSC/TGA)

- Phase characterization and calculation of average grain size of the calcined $\left(400^{\circ} \mathrm{C}\right.$, $600^{\circ} \mathrm{C}$ and $800^{\circ} \mathrm{C}$ ) synthesized powder by X-ray diffraction (XRD)

- Phase characterization of the as-received $\mathrm{TiO}_{2}$ powder calcined at $400^{\circ} \mathrm{C}$ by $\mathrm{XRD}$ 
- Studies of the morphology and particle-size of the synthesized $\mathrm{TiO}_{2}$ powder calcined at $400^{\circ} \mathrm{C}$ by High-resolution Transmission Electron Microscopy (HR-TEM)

- Densification study of the sintered specimens through immersion technique

- Study of phase evolution as a function of sintering temperature by XRD

- Microstructure evolution as a function of sintering temperature by Scanning Electron Microscopy (SEM)

- Characterization of mechanical properties of the sintered specimens through compression and Vickers hardness tests

Figure 1 is a flowchart which gives a view of the research plan adopted and followed in this study. 


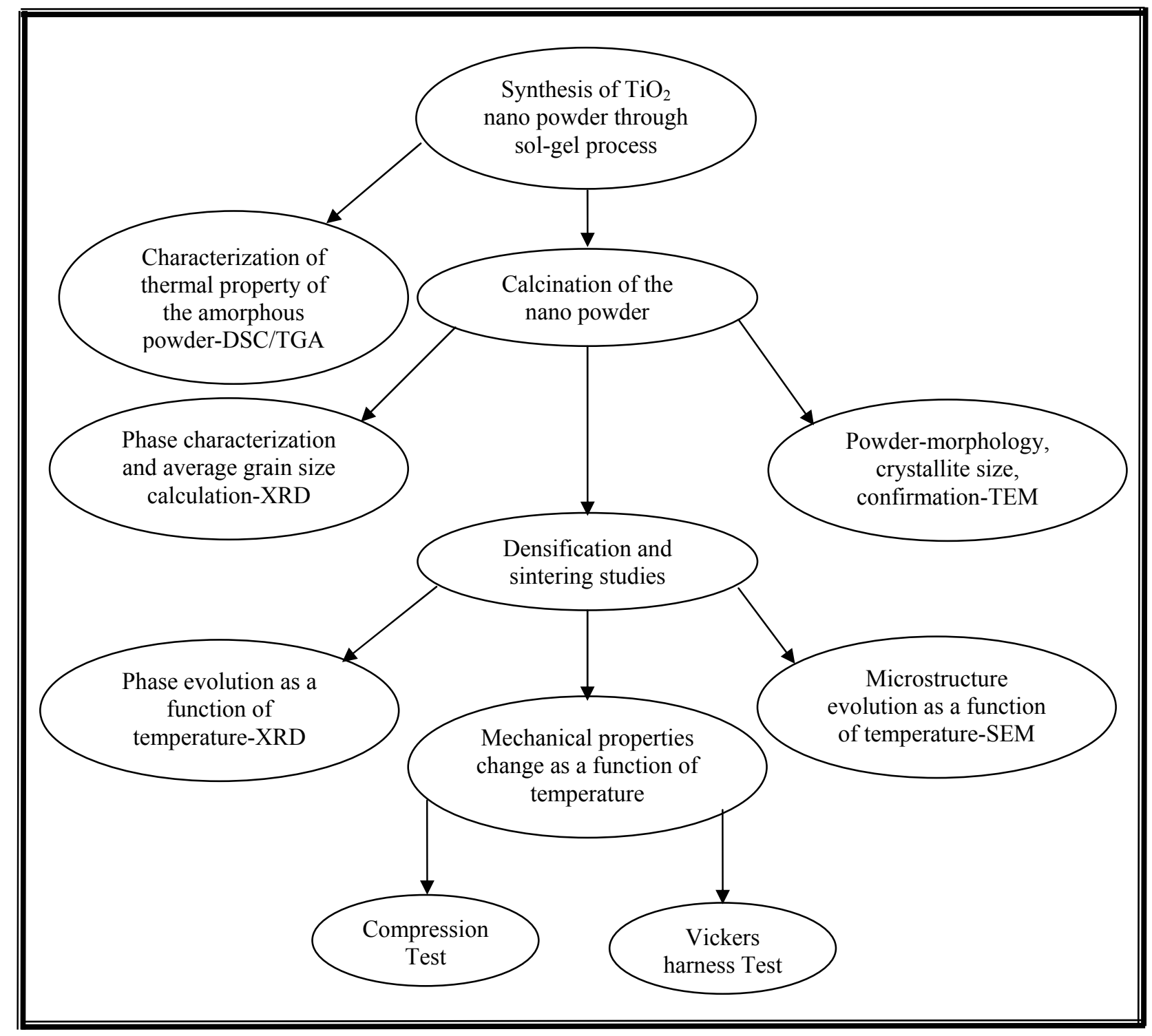

Figure 1. Flowchart of the research plan in this study. 


\section{CHAPTER TWO: LITERATURE REVIEW}

\subsection{Bulk Properties of $\mathrm{TiO}_{2}$}

Since the physical and chemical properties of the material are closely related to and determined by the atomic surface structure, before going into the details concerning on the applications, I would like to introduce the bulk properties of $\mathrm{TiO}_{2}$ first. Due to the mixed ionic and covalent bonding in metal oxide systems, the surface structure has an even stronger influence on local surface chemistry as compared to metals or elemental semiconductors [25]. A great amount of work has been done on $\mathrm{TiO}_{2}$ system in recent years, and has led to a better understanding for its surface behavior.

$\mathrm{TiO}_{2}$ exists in three polymorphs viz., anatase, rutile and brookite (Other structures exist as well, for example, cotunnite $\mathrm{TiO}_{2}$ has been synthesized at high pressures and is one of the hardest polycrystalline materials known [26]). Amongst these, anatase and rutile are of engineering importance because of their unique properties. Their unit cells are shown in Figure

2. Rutile belongs to $D_{4 h}^{14}-\mathrm{P} 4_{2} / \mathrm{mnm}$ space group (lattice constant a $=0.4584 \mathrm{~nm}, \mathrm{c}=0.2953 \mathrm{~nm}$, c/a=0.664), while anatase belongs to $D_{4 h}^{19}-\mathrm{I} 4_{1} /$ amd space group (lattice constant a= $0.3733 \mathrm{~nm}$, $\mathrm{c}=0.937 \mathrm{~nm}, \mathrm{c} / \mathrm{a}=2.51)$ [1]. In both structures, slightly distorted octahedra are the basic building blocks, which consist of a titanium atom surrounded by six oxygen atoms in a more or less distorted octahedral configuration. The bond lengths and angles of the octahedrally coordinated $\mathrm{Ti}$ atoms are indicated and the stacking of the octahedra in both structures is shown in the Figure 2. A considerable deviation from a $90^{\circ}$ bond angle is observed in anatase. In rutile, neighboring 
octahedra share one corner along $<110>$ direction, and are stacked with their long axis alternating by $90^{\circ}$ (see Figure 2). In anatase, (001) planes are formed from the corner-sharing octahedra. They are connected with their edges with the plane of octahedra below. In both $\mathrm{TiO}_{2}$ structures, the stacking sequence of the octahedra results in threefold coordinated oxygen atoms.

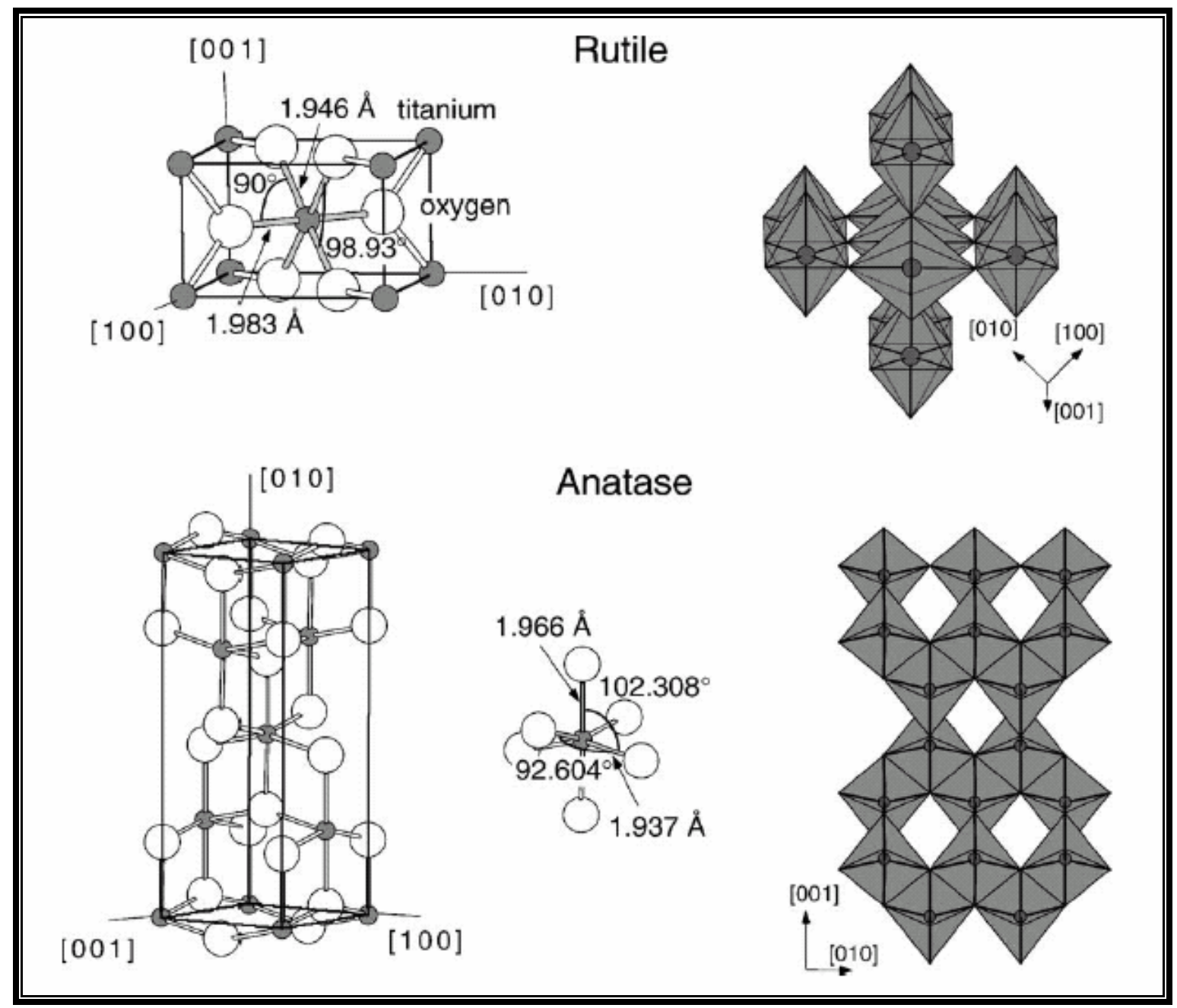

Figure 2. Bulk structures of rutile and anatase [1]. 


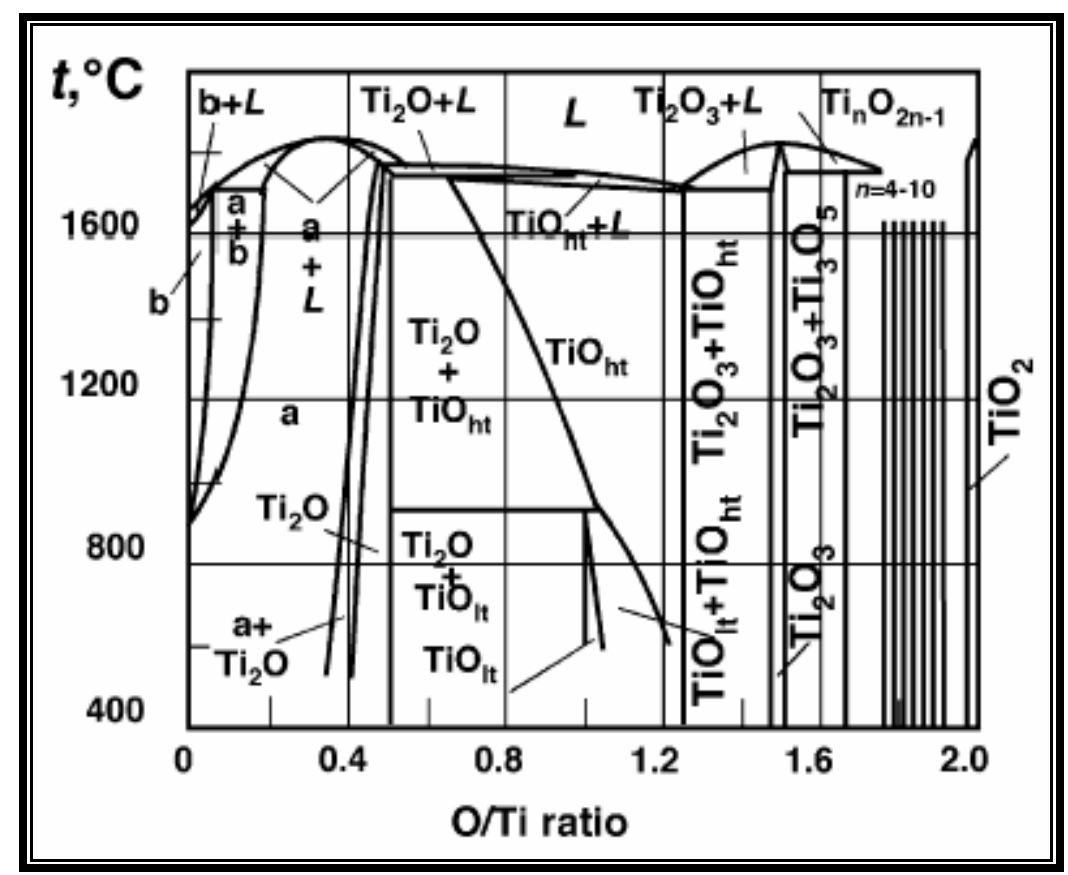

Figure 3. Phase diagram of the Ti-O system [27]. The region $\mathrm{Ti}_{2} \mathrm{O}_{3}-\mathrm{TiO}_{2}$ contains $\mathrm{Ti}_{2} \mathrm{O}_{3}, \mathrm{Ti}_{3} \mathrm{O}_{5}$, seven discrete phases of the homologous series $\mathrm{Ti}_{\mathrm{n}} \mathrm{O}_{2 \mathrm{n}-1}$ (Magneli phases) and $\mathrm{TiO}_{2}$.

The Ti-O phase diagram is composed of many stable phases with a variety of crystal structures, as can be seen in Figure 3 [27]. $\mathrm{TiO}_{2}$ can be reduced easily and the resulting color centers are reflected in a pronounced color change of $\mathrm{TiO}_{2}$ single crystals, from initially transparent to light and, eventually, dark blue. This is an n-type doping, and these intrinsic defects will enable the materials with the property of high conductivity, which makes $\mathrm{TiO}_{2}$ single crystals such a handy oxide system for experimentalists. 


\section{2 $\quad \mathrm{TiO}_{2}$ Photocatalysis}

The extensive knowledge that was obtained during the growth of semiconductor photoelectrochemistry during the 1970 and 1980s has greatly benefited the advance of photocatalysis study [28]. In particular, from several points of view, $\mathrm{TiO}_{2}$ turned out to be an ideal photocatalyst to break down organic compounds. It is relatively inexpensive, highly stable for chemical properties, and the photogenerated holes are highly oxidizing. This hot topic is also reflected from the increasing number of publications every year (Figure 4). Ever since 1977, when Frank and Bard first examined the possibilities of using $\mathrm{TiO}_{2}$ to decompose cyanide in water $[29,30]$, an extensive attention has been developed for its environmental application. These authors quite correctly predicted that the results would be useful in the field of environmental purification. Their prediction has indeed been borne out, as evidenced by the widespread global efforts in this area $[31-35]$.

Like the photoelectric effect, one of the most distinguishing aspects of $\mathrm{TiO}_{2}$ photocatalysis is that, it depends upon the energy, not the intensity, of the incident photons. So the photocatalysis process can be easily induced, even though these are just a few photons of the required energy. This low-intensity light initiating process has yielded a number of exciting and significant conclusions. The first is that the quantum yield for a simple photocatalytic reaction, e.g., 2-propanol oxidation, on a $\mathrm{TiO}_{2}$ film in ambient air, will reach a maximum value even the light intensity is low. So we can achieve minimal recombination losses and high coverage of the adsorbed organic compound [36]. Recent work showed that the measured quantum yield values that could be attributed to a reaction involving hydroxyl radicals were several orders of magnitude smaller than those that could be attributed to reactions involving holes [37]. 


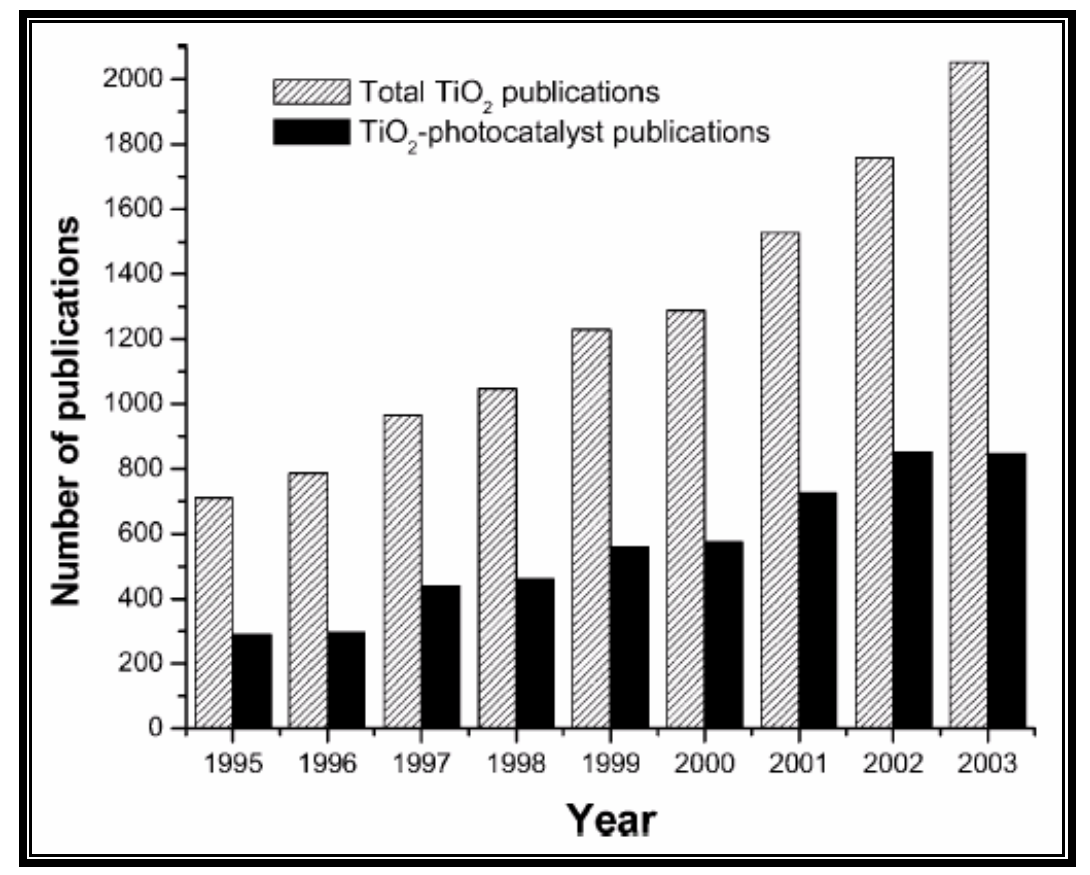

Figure 4. Number of publications regarding $\mathrm{TiO}_{2}$-photocatalysis per year [4].

While some other applications and supporting technologies have been reported in the literature, a large number of applications focusing on photocatalytic technology have been implemented, which are summarized in Table 1 [38] over the past several years. The applications of $\mathrm{TiO}_{2}$ as films [39], containing paper [40], microporous textured $\mathrm{TiO}_{2}$ films [41], self-cleaning $\mathrm{TiO}_{2}$-coated glass covers for highway tunnel lamps [35] and a flow-type photoreactor for water purification have been reported [42]. 
Table 1. Selected applications of $\mathrm{TiO}_{2}$ as photocatalysis [38]

\begin{tabular}{|c|c|c|}
\hline Property & Category & Application \\
\hline \multirow[t]{4}{*}{$\begin{array}{l}\text { Self- } \\
\text { cleaning }\end{array}$} & $\begin{array}{l}\text { Materials for } \\
\text { residential and } \\
\text { office buildings }\end{array}$ & $\begin{array}{l}\text { Exterior tiles, kitchen and bathroom components, interior } \\
\text { furnishings, plastic surfaces, aluminum siding, building } \\
\text { stone and curtains, paper window blinds }\end{array}$ \\
\hline & $\begin{array}{l}\text { Indoor and outdoor } \\
\text { lamps and related } \\
\text { systems }\end{array}$ & $\begin{array}{l}\text { Translucent paper for indoor lamp covers, coatings on } \\
\text { fluorescent lamps and highway tunnel lamp cover glass }\end{array}$ \\
\hline & Materials for roads & Tunnel wall, soundproofed wall, traffic signs and reflectors \\
\hline & Others & $\begin{array}{l}\text { Tent material, cloth for hospital garments and uniforms } \\
\text { and spray coatings for cars }\end{array}$ \\
\hline \multirow[t]{2}{*}{$\begin{array}{l}\text { Air } \\
\text { cleaning }\end{array}$} & Indoor air cleaners & $\begin{array}{l}\text { Room air cleaner, photocatalyst-equipped air conditioners } \\
\text { and interior air cleaner for factories }\end{array}$ \\
\hline & $\begin{array}{l}\text { Outdoor air } \\
\text { purifiers }\end{array}$ & $\begin{array}{l}\text { Concrete for highways, roadways and footpaths, tunnel } \\
\text { walls, soundproof walls and building walls }\end{array}$ \\
\hline \multirow{2}{*}{$\begin{array}{l}\text { Water } \\
\text { purification }\end{array}$} & Drinking water & River water, ground water, lakes and water-storage tanks \\
\hline & Others & $\begin{array}{l}\text { Fish feeding tanks, drainage water and industrial } \\
\text { wastewater }\end{array}$ \\
\hline $\begin{array}{l}\text { Antitumor } \\
\text { activity }\end{array}$ & Cancer therapy & Endoscopic-like instruments \\
\hline \multirow[t]{2}{*}{$\begin{array}{l}\text { Self- } \\
\text { sterilizing }\end{array}$} & Hospital & $\begin{array}{l}\text { Tiles to cover the floor and walls of operating rooms, } \\
\text { silicone rubber for medical catheters and hospital garments } \\
\text { and uniforms }\end{array}$ \\
\hline & Others & Public rest rooms, bathrooms and rat breeding rooms \\
\hline
\end{tabular}




\subsection{Photo-induced Superhydrophilicity}

The more lately discovered unique feature of $\mathrm{TiO}_{2}$ involves high wettability, which is further termed as 'superhydrophilicity'. This effect was in fact discovered accidentally in work that was being carried out at the laboratories of TOTO Inc. in 1995. The phenomenon was that, if a $\mathrm{TiO}_{2}$ film is prepared with a certain amount of $\mathrm{SiO}_{2}$, it acquires superhydrophilic properties after UV illumination. A lot of companies have been trying to develop self-cleaning surfaces, especially windows, for a long period of time. One attempt has been done by trying to make the surface highly hydrophilic, so that a stream of water would be enough to remove stain-causing organic compounds. $\mathrm{TiO}_{2}$ coatings, as long as they are illuminated, can maintain their hydrophilic properties indefinitely, which make the idea of cleaning by a stream of water achievable.

On the studies of superhydrophilic effect, results of friction force microscopy (FFM) on an illuminated rutile single crystal were reported in 1997 [43]. Specifically, it was found that the initially featureless surface become covered with rectangular domains, which were oriented parallel to the (001) direction. Since the $\mathrm{Si}_{3} \mathrm{~N}_{4}$ cantilever tip itself is hydrophilic, the light-shaded domains have the property of hydrophilic by showing greater frictional force. The gray shade of the background indicates that it has remained hydrophobic. Under illumination, the $\mathrm{TiO}_{2}$ surface will become slightly reduced. The general model accounting for this is supported by the fact that ultrasonic treatment can rather rapidly reconvert a hydrophilic surface to the hydrophobic state [44].

Two representative examples of applications for superhydrophilic technology are antifogging surfaces and self-cleaning building materials. 
When humid air condenses, fogging of the surface of mirrors and glass occurs. Many small water droplets formed during the condensation will scatter light. On a superhydrophilic surface, a uniform film of water can form on the surface instead of water droplets, and this film does not scatter light. Depending on the humidity, it is also possible for the water film to be adequately thin that it evaporates rapidly. Mirrors with superhydrophilic coatings maintain their capability for photoinduced wetting semipermanently, at least for several years. With simple processing and at low cost, antifogging function using this new technology has been applied to various glass products, e.g., mirrors and eyeglasses. The opposite approach, i.e., making water droplets to be easily removed by imparting water repellency to the surface of glass, has also been involved with intense research efforts. A superhydrophobic surface was reported recently by Nakajima et al. [45].

Self-cleaning property can now be applied to many different types of surface by means of the superhydrophilic effect. A superhydrophilic surface, even though it is amphiphilic, has a higher affinity for water than for oil when water content is dominant. Based on this characteristic, a kitchen exhaust fan, covered with much oil, could be easily cleaned by water if the fan blades were coated with a superhydrophilic film. Outdoor applications of this technique are also possible. For example, near to highways, the surfaces of the exterior walls of buildings become easily soiled from automotive exhausts, which contain oily components. If the building materials are covered with a superhydrophilic photocatalyst, the walls can be cleaned by spraying water on them or the dirt on the walls can be removed away with rainfall. 


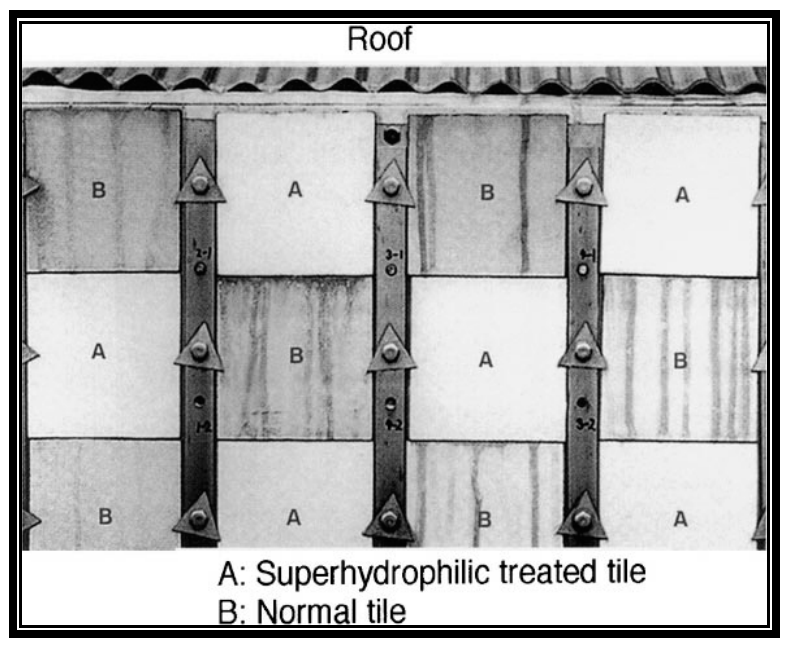

Figure 5. Field test of stain-resistant exterior tiles in polluted urban air [46].

The susceptibility of an exterior building material to soiling is strongly determined by its contact angle with water. A material used on the outside walls of a building is actually more likely to be soiled if it is more hydrophobic. A good example for this is that plastic is more likely to be soiled than glass or tiles, as far as we know. A water-repellent material like a fluorocarbon plastic is the most likely to be soiled. When water contact angle is zero degree, say a superhydrophilic material, it is far less likely to be smeared than any other conditions. Shown in Figure 5 is the smear-resistant effect of a superhydrophilic coating on an exterior concrete wall [46]. Specially treated panels (hydrophilically coated) were mixed with regular concrete panels in a checkerboard pattern. Compared with the regular ones, on which soiling was very conspicuous, the hydrophilically coated panels were not soiled at all. This type of coating is designed to have a life of at least 10 years. 


\section{$2.4 \quad \mathrm{TiO}_{2}$ Sensors}

\subsubsection{Gas sensors}

Semiconducting metal oxides may change their conductivity upon gas adsorption. This change in the electrical signal is used for gas sensing [47-49]. Some gas sensors have already been commercialized in some applications and available on market, which can be seen from Figure 6. $\mathrm{TiO}_{2}$ is not used as extensively as $\mathrm{SnO}_{2}$ and $\mathrm{ZnO}$, but it has received some interest as an oxygen gas sensor, e.g., to control the air/fuel mixture in car engines. In fact, it is one of the most successful applications of an electrochemical sensor found in the exhaust emission control system for the automobile engine. Since the strict regulation was applied to control the air pollution in California in 1965, all gasoline-burning cars are equipped with a catalytic converter, comprising of noble metal catalyst $(\mathrm{Pt}, \mathrm{Pd}, \mathrm{Rh})$ finely dispersed on a ceramic substrate. More than $90 \%$ of the three regulated exhaust toxic pollutants, $\mathrm{NOx}, \mathrm{HC}$, and $\mathrm{CO}$, are eliminated by the catalytic converter (which is hence referred to as a three-way catalyst (TWC)). The best performance of the TWC is obtained for an equivalent air/fuel ratio $(\lambda=\mathrm{A} / \mathrm{F})$ to be at 1 (weight ratio of air to fuel $=14.6$, which can be monitored by the detection of the oxygen content in the exhaust gas upstream from the catalytic converter. Since Ti is such a reactive element, oxygendeficient surfaces are obviously expected to react with $\mathrm{O}_{2}$. In many observations, it has implicitly been supposed that oxygen exposure would just fill surface vacancies of $\mathrm{TiO}_{2}$. It is not until recently that the complexities of the oxygen/defect interaction were studied in more details. At high temperatures, $\mathrm{TiO}_{2}$ can be used as a thermodynamically controlled bulk defect sensor to detect oxygen over a big range of partial pressures. The intrinsic behavior of the defects accounting for the sensing mechanism can be controlled by doping with tri- and pentavalent ions. 
At low temperatures, doping of Pt leads to the formation of a Schottky-diode, which has a high sensitivity against oxygen.

In the recent materials science research, the utilization of nano-sized materials in gas sensors is quickly arousing interest in the scientific community. One reason is that the surface-tobulk ratio for the nano-sized materials is much greater than that for coarse materials. That the conduction type of the material is determined by the grain size of the material accounts for the other reason. When the grain size is small enough (the actual grain size $D$ is less than two times the space-charge depth $L$ ), the material resistivity is determined mainly by grain control, and the conduction type becomes surface conduction type [50]. Therefore, the grain-size reduction becomes one of the main ways in improving the gas-sensing properties of semiconducting oxides.
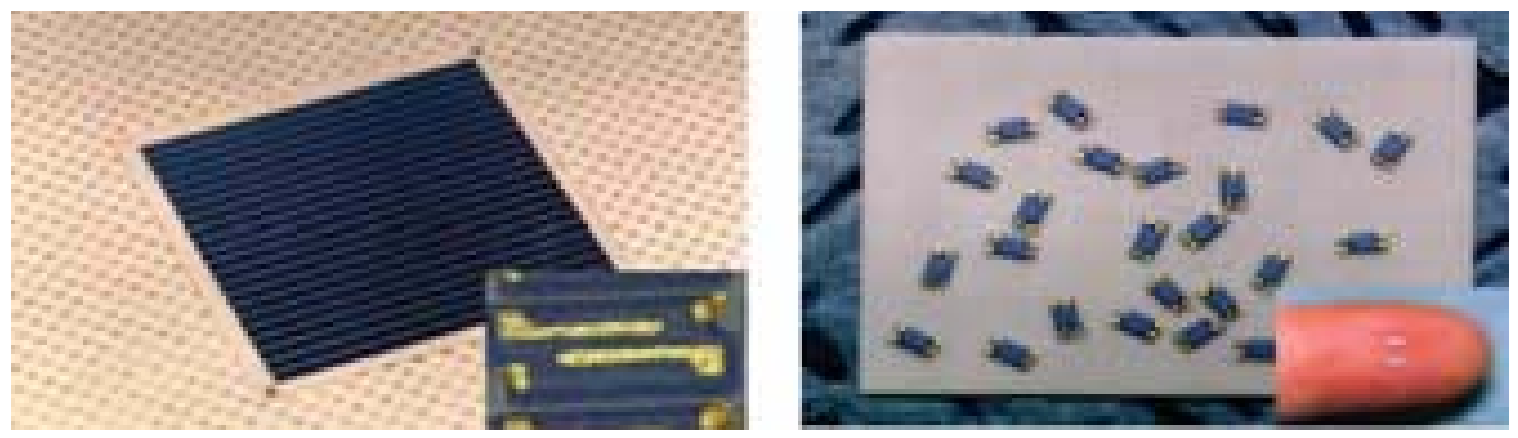

Figure 6. Thick film gas sensors (Adapted from CAOS Inc.)

Compared with other semiconductor oxides, such as $\mathrm{Ga}_{2} \mathrm{O}_{3}, \mathrm{LaF}_{3}, \mathrm{CeO}_{2}, \mathrm{Nb}_{2} \mathrm{O}_{5}, \mathrm{BaTiO}_{3}$, $\mathrm{SrTiO}_{3}$ etc., which show change in their resistivity on exposure to oxygen at different operating temperatures, rutile $\mathrm{TiO}_{2}$ is a potential candidate because of its low cost, phase stability even at 
higher temperature, higher oxygen sensitivity and comparable thermal expansion coefficient to alumina substrate [51]. Further improvement in the sensing performance can be obtained by addition of catalytic noble metals such as $\mathrm{Pt}, \mathrm{Pd}$ or by addition of pentavalent or trivalent dopants. For example, $\mathrm{TiO}_{2}$ doped with chromium has been showed to have enhanced oxygen sensing properties [52].

\subsubsection{Humudity sensors}

Numerous kinds of materials have been used for these sensors, and new ones are continually being recommended. A resistive humidity sensor based on $\mathrm{MgCr}_{2} \mathrm{O}_{4}-\mathrm{TiO}_{2}$ was developed for practical use in microwave ovens in 1978 [53]. The sensing element is a small, porous ( $35 \%$ porosity, with an average pore size of $300 \mathrm{~nm}$ ) rectangular wafer made of a $\mathrm{MgCr}_{2} \mathrm{O}_{4}-\mathrm{TiO}_{2}$ spinel solid solution with $35 \mathrm{~mol} \%$ of $\mathrm{TiO}_{2}$, porous $\mathrm{RuO}_{2}$ electrodes and a coil heater for self-cleaning. The wafer is heat cleaned at $500^{\circ} \mathrm{C}$ before each operation in order to get rid of the surface hydroxyl groups, which may impede Grotthuss-type conduction, resulting in a drift of the resistance of the element.

Many investigations were carried out in $\mathrm{TiO}_{2}$-based humidity sensitive materials as porous bodies. Generally, the results obtained from pure $\mathrm{TiO}_{2}$ were not totally acceptable because of the high resistivity of $\mathrm{TiO}_{2}$ and its poor long-term stability [54]. However, Yeh et al. reported that sintered $\mathrm{TiO}_{2}$ structures with $35 \%$ open porosity can be reversibly operated without repeated heat cleaning [55]. The addition of $\mathrm{Nb}_{2} \mathrm{O}_{5}(0.5 \mathrm{~mol} \%)$ to $\mathrm{TiO}_{2}$ was later studied and found that the humidity sensitivity was significantly influenced by the microstructure, which was varied by changing the sintering temperatures [54]. 
The application of porous $\mathrm{La}_{2} \mathrm{O}_{3}-\mathrm{TiO}_{2}-\mathrm{V}_{2} \mathrm{O}_{5}$ ceramics has recently been proposed for humidity sensors [56]. This is a phase-separable glass system, and the appealing characteristic of this system is that it is possible to control the microstructure of the resulting porous glass by inducing phase separation through heat treatment, and subsequent leaching to wash out the soluble phase. In addition, it is also feasible to select from the various glass-ceramic systems that have suitable intrinsic impedance. Humidity sensitivity up to three orders of magnitude in the form of impedance changes, as well as good linearity of the logarithm of impedance in the whole detecting range, has been reported. However, the shortest response time obtained was 3 min, which is far from satisfaction, so related research is still going on in this field.

\subsection{Synthesis of Nanomaterials}

Nanomaterials are characterized by at lease one dimension in the nanometer range. Nanostructures constitute a bridge between molecules and infinite bulk systems. Individual nanostructures include clusters, quantum dots, nanocrystals, nanowires, and nanotubes, while collections of nanostructures involve arrays, assemblies, and superlattices of the individual nanostructures [57]. The physical and chemical properties of nanomaterials can change significantly from those of the atomic-molecular or the bulk materials with the same composition. The uniqueness of the structural characteristics, energetics, response, dynamics, and chemistry properties of nanostructures constitutes the basis of nanoscience. Manipulated control of the properties and response of nanostructures can lead to new devices and technologies. The synthesis of nanosized materials is usually done in following two approaches: 1. Bottom-up approach 


\section{Top-down approach}

Bottom-up approach consists of chemical synthesis, chemical vapor deposition, thermal spray technique, inert gas condensation, rapid solidification and electrodeposition. Bottom-up synthesis approach utilizes the phenomenon of assembly of atoms or particles. Top-down approach consists of processes like mechanical alloying/milling, wear, devitrification and spark erosion. Chemical reactions for material synthesis can be carried out in the solid, liquid or gaseous state [58]. Wet chemical synthesis process results in fast diffusion of matter in the liquid phase, which is several times faster than solid phase, thus leading to synthesis of nanostructured materials at low temperatures. Vapor condensation or evaporation process consists of heating a metal or chemical to high temperatures under high vacuum conditions. The vaporized atoms collide with each other in the high vacuum chamber, lose the kinetic energy, and condense in the form of powder. The powder size and morphology depends on process variables like substrate temperature and vacuum conditions. Fine powders synthesized can be allowed to react with gases to form oxides, nitrides, carbides, sulphides etc.

As mentioned above, different preparation methods have been developed and used to synthesize nanoscale $\mathrm{TiO}_{2}$ powders, which include chemical vapor deposition (CVD) [11-13], oxidation of titanium tetrachloride [14,15], thermal decomposition and sol-gel technique via hydrolysis of titanium alkoxides [16]. Among these methods, the sol-gel process offers unique advantages. This process uses precursors or starting compounds for preparation of a colloid consisting of a metal or a metalloid element surrounded by various ligands. It involves hydrolysis and condensation of precursors of traditional metal alkoxides. The condensation reaction leads to the formation of gel. Sol-gel processes can be used to prepare the material in a 
variety of forms, like powders, films, fibers, glass and monoliths. Two types of sol-gel approaches of synthesizing $\mathrm{TiO}_{2}$ are known: the non-alkoxide and the alkoxide route. The nonalkoxide route uses inorganic salts (such as nitrates, chlorides, acetates and carbonates), which requires an additional removal process for the inorganic anion; while the alkoxide route uses metal alkoxides as starting material, which are highly preferred. Processing conditions, such as chemical concentration, the $\mathrm{pH}$, peptization time, calcinations time and temperature have a great influence on the particle size and phase purity of the final powder.

\subsection{Sintering of Nanopowder}

Synthesis, characterization and processing of nanocrystalline materials are part of a fast emerging and rapid growing field in nanoscience and nanotechnology. Nanocrystalline materials show interesting properties due to their high surface-volume ratio [59]. Ceramic nanostructures have changed the approach to materials design in many applications by seeking structural control at atomic level and tailoring of the engineering properties [60]. As the particle size decreases a higher proportion of atoms exist at the interfaces, i.e., either the free interfaces (surface) or the internal interfaces (grain boundaries) (Figure 7 (a) and (b)). The boundaries can be considered as defects where a misfit between adjacent crystallites changes the atomic structure (the average atomic density, coordination number etc) relative to a perfect crystal. Therefore, more atoms have coordination number different from atoms at the grain interiors. Since bonding and interaction among the constituent atoms play a major role in determining the properties of a material, a lower coordination number for an increased number of atoms results in special material properties for nanomaterials, which are different from their bulk counterparts. 


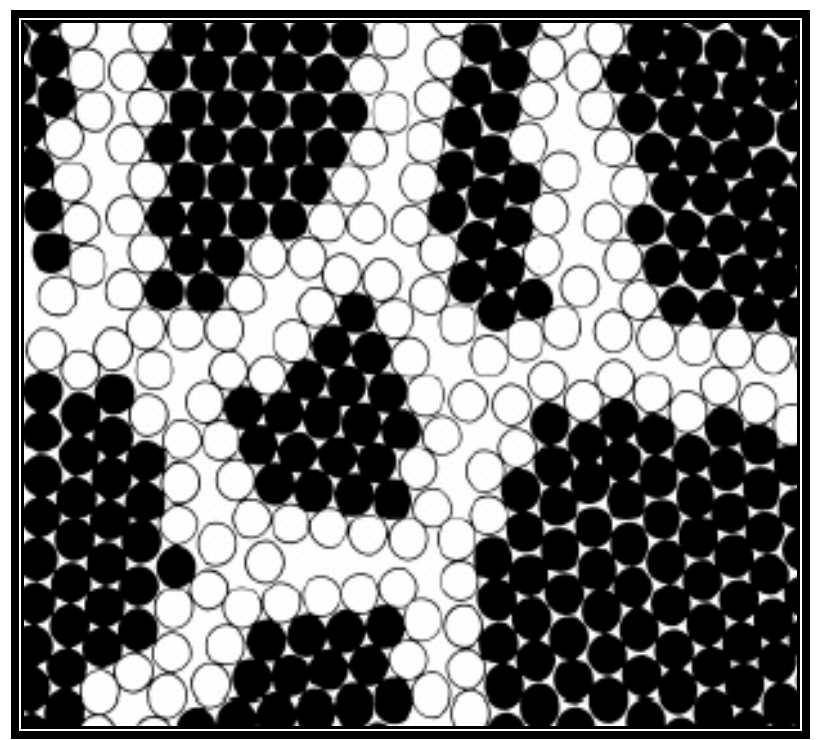

(a)

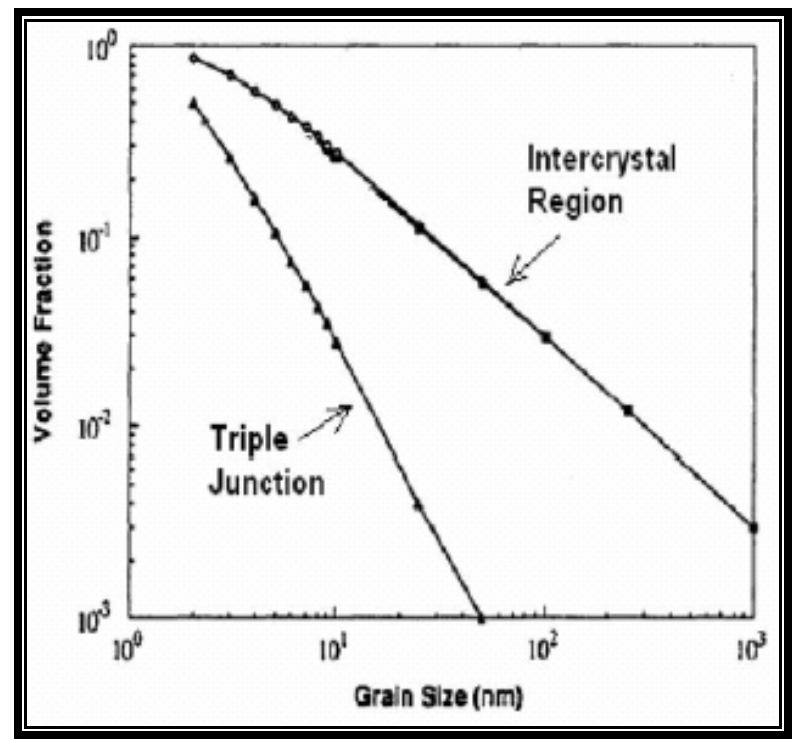

(b)

Figure 7. (a) Atomic structure of a nanostructured material developed by computational modeling. The black atoms are atoms the sites of which deviate by more than $10 \%$ from the corresponding lattice sit. (b) Effect of grain size on calculated volume fractions of intercrystal regions and triple junctions, assuming grain boundary width of $1 \mathrm{~nm}$ [59].

The main goal during sintering of nanomaterials is to maintain their nanosized $(<100$ $\mathrm{nm})$ and their unique features that nanoscience offers. Challenges associated with nanosintering are due to following reasons [61]:

1. Particle agglomeration,

2. High reactivity and inherent contamination,

3. Grain coarsening and

4. Ultimate loss of the nanofeatures. 
Decrease in particle size results in an increase in the surface area and consequently an increase in the surface free energy, which renders the nanoparticles highly active. This leads to nanoparticles adopting different surface energies than regular ones, for example, by a different local atomic arrangement on the surface. TEM studies showed that nanoparticles have a faceted appearance with anisotropic surface energies. Kinetically, sintering of nanopowders can be significantly enhanced because of the higher surface energies. Consequently, sintering of nanoparticles will show depressed sintering onset temperatures $(0.2-0.3 \mathrm{Tm})$ as compared to conventional powders (0.5-0.8 Tm). Molecular dynamics (MD) simulations indicated extremely fast sintering can be achieved for nanoparticles.

Nanomaterials tend to agglomerate to reduce the total surface energy. Major challenge in processing of nanopowder is to produce bulk quantity of nanopowder with minimal or no agglomeration [62]. Problems arise during powder compaction due to presence of hard agglomerated particles, high plastic yield, resistance to motion under pressure and contamination of particle surfaces. Compaction through conventional processes involves certain amount of sliding and rearrangement, both of which become increasingly difficult as particle size decreases. On the nanoscale, the relative motion and rearrangement between particles become difficult due to the frictional forces.

For nanopowder densification, some pressure-assisted consolidation methods have also been applied: hot pressing, sinter forging, hot isostatic processing (HIP), extrusion, and high pressure techniques. Among them, sinter forging has been extensively applied to nanoceramic $\mathrm{TiO}_{2}$ particle consolidation [63-66]. Generally, the stress levels needed for densification by sinter forging are lower than those in hot pressing or HIP. The most attractive advantage in using the 
sinter forging technique is that the green compacts can be densified with large interagglomerate pores inside. The high shear stresses associated with uniaxial pressure application contribute to the closure of large pores that cannot otherwise be eliminated by diffusion only.

\subsection{Mechanical Behavior of Nanocrystalline Materials}

One of the most outstanding properties of nanostructured materials is their extremely high hardness and strength, which makes them ideal for structural applications where strength and weight are important. The intensive enthusiasm for research on the mechanical behavior of nanocrystalline materials is driven by both scientific interest and their technological promise. When talking about mechanical behavior, it would be interesting to know if dislocation activity, which dominates deformation mode in coarse-grained ductile materials, still plays a significant role as grain sizes go down to tens of nanometers, and if new deformation modes that cannot be activated in coarse-grained materials appear. From the application point of view, with the increasing number of applications of nanocrystalline materials in micro-electromechanical systems (MEMS), micro/nano devices, precise cutting tools, surface coating, and highperformance structural applications, it is imperative to build up a detailed understanding of the intrinsic mechanical behavior and underlying deformation mechanisms that govern the mechanical response of nanocrystalline materials. This fundamental knowledge would help to model and predict mechanical performance and to design for the use of nanocrystalline materials in devices.

It is well known that the yield strength of coarse-grained metals follows, almost without exception, the Hall-Petch equation which correlates grain size with strength 


$$
\sigma=\sigma_{0}+k D^{-1 / 2}
$$

where $\sigma$ is the yield strength, $\mathrm{D}$ the average grain size in diameter, $\sigma_{0}$ the "friction stress" representing the overall resistance of the crystal lattice to dislocation movement, and the HallPetch slope $k$ is a constant that depends on the material. And the strength of the material has been found to increase with decreasing grain size, approximately following this relationship. However, the reasons that the continued Hall-Petch type strengthening down to nanoscale grain sizes are not fully understood yet are that dislocation sources are not expected to operate within the tiny nanocrystalline grains, and there is no confirmation from experimental studies, that dislocation pileups will be formed in deformed nanocrystalline specimens. While the strengthening continues with decreasing grain size, several reports claim that below a grain size of $\sim 10 \mathrm{~nm}$, strength decreases with further grain refinement (the so-called "inverse Hall-Petch" relationship) [67-69]. The challenge of verifying such kind of behavior arises from the fact that reliable mechanical testes are very difficult to achieve in samples with $d$ in the order of a few nanometers. They have to be fully densified, free of contaminations, preferably in bulk form, and the grains should be equiaxed with uniform sizes. When every large stresses are applied, the grain boundary sliding and grain rotation may also become active at grain sizes below $10 \mathrm{~nm}$, and thus could considerably contribute to deformation. So there is a strong possibility that the extension of Hall-Petch models to nanocrystalline grain sizes may not be justified. Related research in setting up proper models of predicting mechanical properties and modes of deformation in this grain size regime are still going on. 


\subsection{Rietveld Refinement Technique}

The Rietveld refinement technique [70], which was originally introduced for the analysis of constant wavelength neutron diffraction data [71], is being broadly used for the analysis of neutron, X-ray and synchrotron diffraction data nowadays. This technique, implemented in the LANL code General Structure Analysis System (GSAS) [72], will also be used to analyze X-ray diffraction spectra in our studies. In the Rietveld method, the intensity at every point in the spectrum is determined by adding the calculated background and Bragg scattering intensities corresponding to diffraction peaks. The refinement procedure varies selected parameters (e.g., phase volume fractions, lattice parameters, and phase texture, etc.), and constructs linear constraints between parameters (e.g., atomic fraction of $\mathrm{A}+$ atomic fraction of $\mathrm{B}=1$ ), until the calculated and measured spectra match in a least-squares fit. Errors are quantified and are associated with the statistics of the fit. As is shown in Figure 8, the observed diffraction intensities are displayed as crosses in red, with the calculated values drawn as a curve in green. The reflection positions are marked and the difference curve $\left(I_{0}-I_{c}\right)$ in purple is displayed near the bottom of the graph. Furthermore, Rietveld refinement can account for variations in intensity due to changes in phase volume fractions (in multiphase materials) or to preferred orientation (texture). A generalized spherical harmonic description $[73,74]$ will be used to account for the evolving texture in the existing phases. 


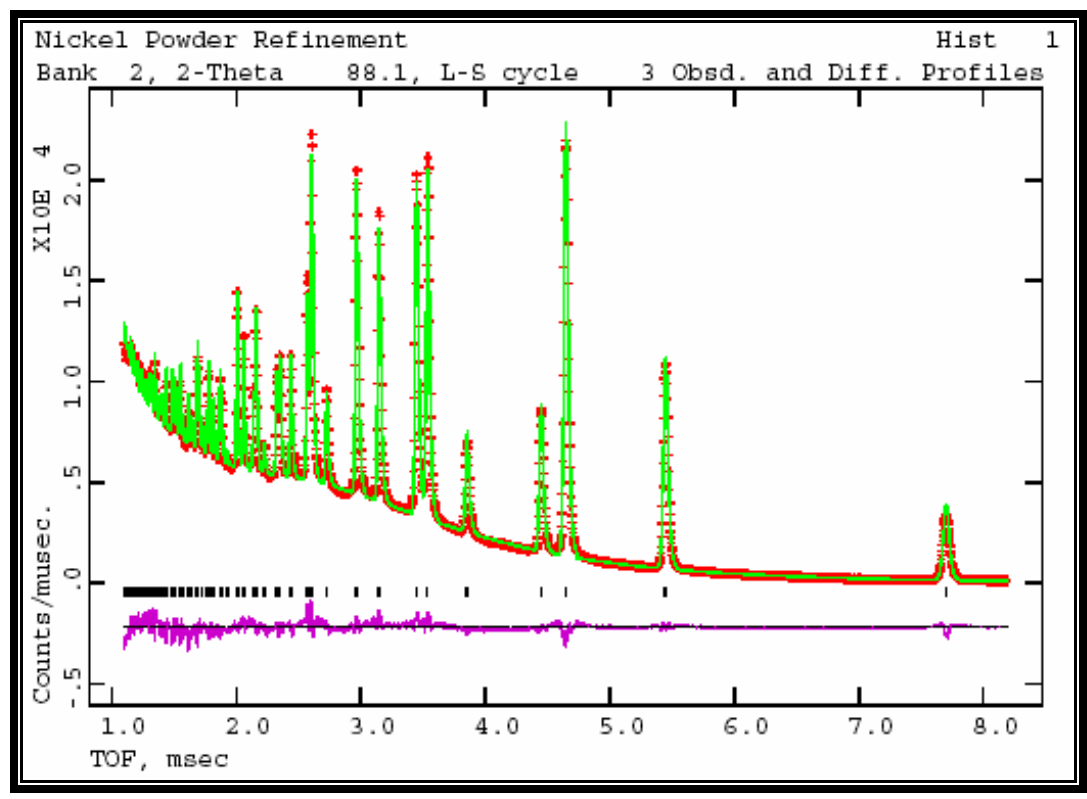

Figure 8. Rietveld refinement of diffraction pattern corresponding to nickel powder [75] 


\section{CHAPTER THREE: METHODOLOGY}

In this chapter, the complete procedure of the experiment is introduced in details, starting from the raw materials selection, synthesis and characterization of the as-synthesized and calcined nano- $\mathrm{TiO}_{2}$ powder, to powder consolidation and characterization of the sintered structures.

\subsection{Raw Materials Used}

Table 2. Chemicals used in the experiments

\begin{tabular}{llll}
\hline Chemical Name & Molecular Formula & Purity & Company \\
\hline $\begin{array}{l}\text { Titanium (IV) } \\
\text { tetraisopropoxide }\end{array}$ & $\mathrm{Ti}\left[\mathrm{OCH}\left(\mathrm{CH}_{3}\right)_{2}\right]_{4}$ & $98+\%$, solution & $\begin{array}{l}\text { Fisher Scientific, } \\
\text { USA }\end{array}$ \\
$\begin{array}{llll}\text { Isopropanol } \\
\text { Nitric acid }\end{array}$ & $\mathrm{CH}_{3} \mathrm{CH}(\mathrm{OH}) \mathrm{CH}_{3}$ & $70 \%$, solution & $\begin{array}{l}\text { Fisher Scientific, } \\
\text { USA }\end{array}$ \\
& $\mathrm{HNO}_{3}$ & $6 \mathrm{M}$, solution & $\begin{array}{l}\text { Fisher Scientific, } \\
\text { USA }\end{array}$ \\
$\begin{array}{l}\text { Deionized water } \\
\mathrm{H}_{2} \mathrm{O}\end{array}$ & & - & $\begin{array}{l}\text { Fisher Scientific, } \\
\text { USA }\end{array}$ \\
& & & Alfa Aesar, USA \\
\hline
\end{tabular}

Table 2 gives details of the purity and source of the staring chemicals used in this experiment. Different kinds of precursors can be used to synthesize $\mathrm{TiO}_{2}$ through Sol-Gel technique, for example, tetra-n-butyl-titanate, $\mathrm{TiCl}_{4}$, etc. In our experiment, we chose titanium isopropoxide $\mathrm{Ti}\left(\mathrm{OC}_{3} \mathrm{H}_{7}\right)_{4}$ (also noted as TTIP) as the precursor to start with. This solution is 0.95 
$\mathrm{g} / \mathrm{cm}^{3}$ in density, with a sensitive nature to moisture. The chemical structure can be referred to Figure 9.

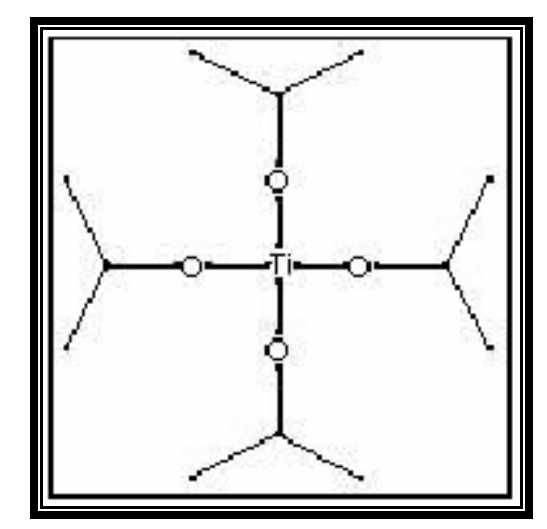

Figure 9. Chemical structure of titanium isopropoxide

\subsection{Synthesis of Nanopowder}

Nano-sized $\mathrm{TiO}_{2}$ powder was synthesized via a Sol-Gel method using titanium tetraisopropoxide (TTIP), isopropanol and deionized water as starting materials. A fixed amount of a mixture of isopropanol and deionized water $\left(\mathrm{M}_{\text {Isopropanol }}: \mathrm{M}_{\mathrm{TTIP}}: \mathrm{M}_{\mathrm{H} 2 \mathrm{O}}=1: 2: 12\right)$ was added in drops into TTIP solution while magnetic stirring was applied at the same time. When the titration process finished, nitric acid was added into the aqueous solution. $\mathrm{pH}$ of the solution was maintained at 2.0. The acid was used to restrain the hydrolysis process and consequently, to control the grain growth [76]. The solution was stirred at high speed for another $1 \mathrm{~h}$ and peptized overnight. After peptization, a two-layer solution was seen to be formed: the upper layer being, the organic by-product of the hydrolysis, and the lower layer a titanic acid gel. The gel was then collected by filtration and dried at $110^{\circ} \mathrm{C}$ for several hours, until yellow block crystals appeared. 
These crystals were crushed and ground into fine powder using a mortar and pestle and further calcined at $400^{\circ} \mathrm{C}$ for $3 \mathrm{~h}$. A process flow chart depicting the synthesis of nanocrystalline $\mathrm{TiO}_{2}$ is shown in Figure 10. The hydrolysis reaction leading to the formation of $\mathrm{TiO}_{2}$ can be represented by the following reaction (2):

$$
\mathrm{TTIP}+2 \mathrm{H}_{2} \mathrm{O} \rightarrow \mathrm{TiO}_{2}+4 \mathrm{C}_{3} \mathrm{H}_{7} \mathrm{OH}
$$

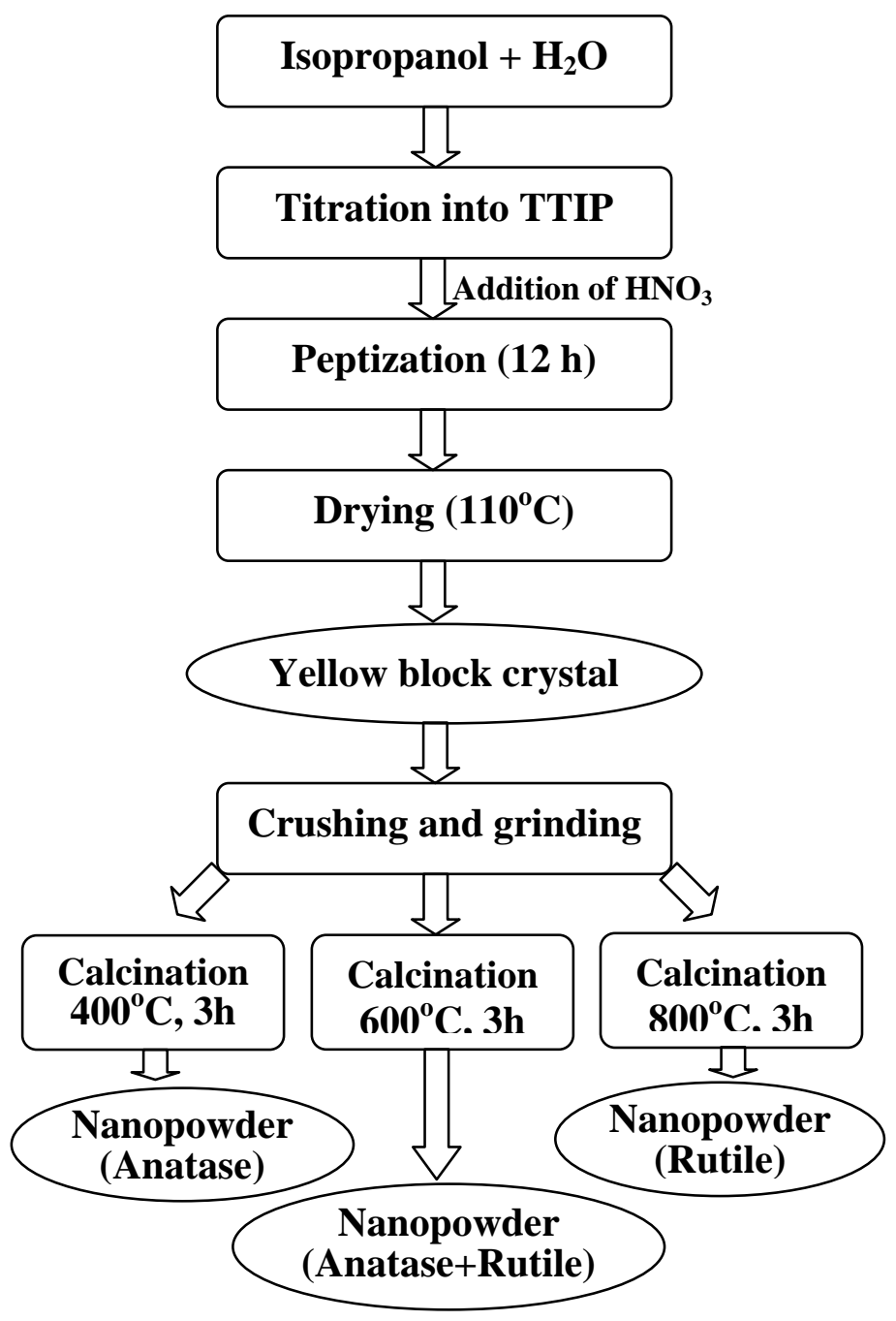

Figure 10. Flow chart showing preparation of nano- $\mathrm{TiO}_{2}$ powders through a Sol-Gel process. 


\subsection{Powder Characterization}

\subsubsection{Characterization of as-received $\mathrm{TiO}_{2}$ (anatase) powder}

The as-received $\mathrm{TiO}_{2}$ powder was first subjected to a 3 h's calcination at $400^{\circ} \mathrm{C}$, after which the phase characterization and calculation of average grain size of were performed with the aid of XRD technique. XRD patterns were recorded in the $2 \theta$ range of 20-70 degrees with an automated X-ray diffractometer (Model D/MAX-B, Rigaku Co., Tokyo, Japan) using Cu K $\alpha$

radiation $(\lambda=1.5418 \AA)$ in the step scanning mode, with tube voltage of $35 \mathrm{kV}$ and tube current of $30 \mathrm{~mA}$. The $2 \theta$ step size was $0.04^{\circ}$ and a scanning rate of $1.5 \mathrm{deg} / \mathrm{min}$ was used. Phase identification was carried out by comparing the observed XRD pattern with the expected pattern available from Powder Diffraction Files.

\subsubsection{Characterization of synthesized $\mathrm{TiO}_{2}$ nano-powder}

Differential Scanning Calorimetry / Thermal Gravimetric Analysis (DSC/TGA) was used to characterize the thermal properties of the synthesized amorphous powder. X-Ray Diffraction (XRD) and Transmission Electron Microscopy (TEM) were further carried out on the calcined nanopowder to get the information on structure, phase evolution, phase transformation from anatase to rutile, and morphology.

\subsubsection{Differential scanning calorimetry / thermal gravimetric analysis}

Thermal behavior of the synthesized amorphous powder dried at $110^{\circ} \mathrm{C}$ was analyzed through DSC and TGA studies. The DSC and TGA analysis of the sample were performed from ambient temperature to $900^{\circ} \mathrm{C}$ using a DSC/TGA analyzer (Model SDT Q600, TA Instruments 
Inc., New Castle, DE) with a heating rate of $6^{\circ} \mathrm{C} / \mathrm{min}$. During the measurements, pure nitrogen $\left(\mathrm{N}_{2}\right)$ was used as a purging gas at a speed of $10 \mathrm{~cm}^{3} / \mathrm{min}$.

\subsubsection{X-ray diffraction}

Phase characterization and calculation of average grain size of the synthesized powder calcined at $400^{\circ} \mathrm{C}, 600^{\circ} \mathrm{C}$ and $800^{\circ} \mathrm{C}$ were performed based on XRD technique, using the same X-ray diffractometer and parameters as above (Model D/MAX-B, Rigaku Co., Tokyo, Japan).

According to C. Suryanarayana [77], broadening of X-ray diffraction peaks mainly due to three factors:

1. Instrumental effects: These effects include imperfect focusing, unresolved $\alpha 1$ and $\alpha 2$ peaks, or the finite widths of the $\alpha 1$ and $\alpha 2$ peaks in cases where the peaks are resolved.

2. Crystallite size: Small crystallite sizes can introduce additional broadening into the diffraction peaks.

3. Lattice strain: The lattice strain in the material also causes broadening of the diffraction peaks, which can be represented by the relationship

$$
\mathrm{B}_{\text {strain }}=\eta \tan \theta
$$

where is $\eta$ the strain in the material. From the above consideration, in order to accurately calculate the sizes of small grains, the peak broadening due to lattice strain and the instrument should be subtracted. Once the instrumental peak width is subtracted from B (the peak width at 
half maximum intensity, which can be measured directly from the X-ray reflections), the remaining peak width, $\mathrm{B}_{\mathrm{r}}$ will be due to the combination of crystallite (grain) size and lattice strain, i.e.,

$$
\mathrm{B}_{\mathrm{r}}=\mathrm{B}_{\text {crystallite }}+\mathrm{B}_{\text {strain }}
$$

Further, according to the Scherrer equation,

$$
\mathrm{B}_{\text {crystallite }}=\mathrm{k} \lambda / \mathrm{L} \cos \theta
$$

where $\mathrm{k}$ is a constant (usually taken as 0.9 ), $\lambda$ is the $\mathrm{X}$-ray wavelength, $\mathrm{L}$ is the average particle size, and $\theta$ is the Bragg angle. By combining the above three equations, we will have:

$$
\mathrm{B}_{\mathrm{r}}=\mathrm{k} \lambda / \mathrm{L} \cos \theta+\eta \tan \theta
$$

Thus by plotting $\mathrm{B}_{\mathrm{r}} \cos \theta$ against $\sin \theta$, one obtains a straight line, whose slope is $\eta$, and the intercept on the $\mathrm{Y}$-axis is $\mathrm{k} \lambda / \mathrm{L}$, from which the value of $\mathrm{L}$ can be obtained.

\subsubsection{High-resolution transmission electron microscopy}

The morphology and powder particle-size of the synthesized $\mathrm{TiO}_{2}$ powder (calcined at $400^{\circ} \mathrm{C}, 3 \mathrm{~h}$ ) were characterized using HR-TEM (Model Tecnai - Philips F30, FEI Co., Hillsboro, OR). The machine has a resolution of $0.20 \mathrm{~nm}$ point to point and can capture images with a 
maximum magnification of $10,000,000 \mathrm{X}$. It operates with a field emission gun and can operate at a maximum voltage of $300 \mathrm{KV}$. Dispersion of the powder for TEM study was accomplished by suspending the powder in deionized water, and then putting a drop of this suspension onto a formvar-carbon film on a copper grid.

\subsection{Powder Consolidation}

Powder calcined at $400^{\circ} \mathrm{C}$ for $3 \mathrm{~h}$ was used as starting material for compaction and sintering studies. Cold compaction was used to press the powder into pellets with desired dimension for further study.

\subsubsection{Cold Uniaxial Compaction}

Ceramic powders were compacted by a traditional cold die compaction method and then sintered at various temperatures. During the cold die compaction, the powder is densified by powder rearrangement, including sliding and rolling, so as to decrease the porosity. Since nanoceramic powders have a tendency to form agglomerates, it is sometimes necessary to grind the powders first to break the agglomeration.

After calcination, nano- $\mathrm{TiO}_{2}$ powder was compacted into cylindrical structures (green samples) in a uniaxial single action manual hydraulic press (Model 3851-0, CARVER INC., Wabash, IN) by using a brass mold at a pressure of $126 \mathrm{MPa}$ for densification studies and mechanical characterization. A dry P.T.F.E film (made with Dupont Krytox) was sprayed on the inside surface of the brass mold and punch to reduce the friction between the fine powder and metal surfaces. Samples intended for densification studies and hardness test had an average 
dimension of $9.5 \mathrm{~mm}$ in diameter and $3.2 \mathrm{~mm}$ in thickness, while samples for compression test had an average dimension of $9.5 \mathrm{~mm}$ in diameter and $13.0 \mathrm{~mm}$ in thickness. Cylindrical green samples of commercial $\mathrm{TiO}_{2}$ powder were also prepared for comparison of their densification behavior at different sintering temperatures.

\subsubsection{Sintering of Compacted Structures}

All green samples were then sintered in a high temperature programmable muffle furnace (Model 46100, Barnstead International Co., Dubuque, IA) in an ambient atmosphere, at a temperature range of $1100^{\circ} \mathrm{C}-1600^{\circ} \mathrm{C}$ for $3 \mathrm{~h}$. A sintering cycle suitable for $\mathrm{TiO}_{2}$ ceramics was developed to attain improved densification and to avoid cracks in the sintered specimens by introducing several soaking temperatures and tailoring the rate of heating and cooling. The consequent cycle had several steps: first, holding at $150^{\circ} \mathrm{C}$ to stabilize the furnace; second, holding at $400^{\circ} \mathrm{C}$ to remove residual stresses from the green structures; and the final holding at the desired sintering temperature $\left(1100^{\circ} \mathrm{C}-1600^{\circ} \mathrm{C}\right.$ for $\left.3 \mathrm{~h}\right)$ for densification. A heating rate of $6^{\circ} \mathrm{C} / \mathrm{min}$ and a cooling rate of $10^{\circ} \mathrm{C} / \mathrm{min}$ were used to reduce any thermal stress-induced cracking during sintering and to improve densification.

\subsection{Characterization of the Sintered Structures}

\subsubsection{Densification Study}

Sintered specimens were measured for their geometric bulk density $\left(\rho_{\mathrm{g}}\right)$, volumetric bulk density $\left(\rho_{\mathrm{v}}\right)$, apparent density $\left(\rho_{\mathrm{a}}\right)$ and apparent porosity $\left(\xi_{\mathrm{a}}\right)$. Geometric bulk density $\left(\rho_{\mathrm{g}}\right)$ was evaluated from the ratio between the mass of specimen and its volume (determined by 
dimensional measurements). Volumetric bulk density $\left(\rho_{\mathrm{v}}\right)$, apparent density $\left(\rho_{\mathrm{a}}\right)$ and apparent porosity $\left(\xi_{\mathrm{a}}\right)$ were evaluated by using equations (7), (8) and (9) through immersion technique [78].

$$
\begin{aligned}
& \xi_{\mathrm{a}}(\%)=100\left[\left(m_{s}-m_{d}\right) /\left(m_{s}-m_{i}\right)\right] \\
& \rho_{\mathrm{v}}\left(\mathrm{g} / \mathrm{cm}^{3}\right)=\left[m_{d} /\left(m_{s}-m_{i}\right)\right] \rho_{\mathrm{L}} \\
& \rho_{\mathrm{a}}\left(\mathrm{g} / \mathrm{cm}^{3}\right)=\left[m_{d} /\left(m_{d}-m_{i}\right)\right] \rho_{\mathrm{L}}
\end{aligned}
$$

where $m_{i}, m_{s}$ and $m_{d}$ represented immersed, saturated and dry masses of the sample, respectively. $\rho_{\mathrm{L}}$ was liquid's density. $\rho_{\mathrm{v}}$ of the sintered specimens was calculated in addition to $\rho_{\mathrm{g}}$, as $\rho_{\mathrm{v}}$ provided better accurately than $\rho_{\mathrm{g}}$. Pure water was used when measuring the apparent density in this case. In order to correlate macroscopic physical property with microstructure observed in SEM, $\rho_{\mathrm{a}}$ and $\xi_{\mathrm{a}}$ were measured. $\rho_{\mathrm{a}}$ is the ratio of the mass in air to a given volume (excluding the open voids but including the closed voids normal to the material) at a stated temperature, while, porosity is the measure of the percentage of water permeable voids in a compacted sample. In this technique, sintered samples were thoroughly washed first to remove dusts from the surfaces and soaked in water for $24 \mathrm{~h}$. Then the samples were removed from the water, drained off the free water for a few seconds and transferred to a large absorbent cloth. In order to obtain the socalled saturated surface-dry condition, the samples were rolled in the cloth until all visible water had been absorbed, but the surfaces still appeared damp. As soon as the surface-dry condition 
was reached, the samples were weighed for their saturated mass $\left(m_{s}\right)$ by using Ohaus Adventurer analytical balance (Model AR-2140, Ohaus Co., NJ), accurate to $0.0001 \mathrm{~g}$. Then, the samples were transferred to a wire basket that had previously been weighed in water. The basket was again measured for total weight in water at $25 \pm 1{ }^{\circ} \mathrm{C}$ and insured that no air was entrapped. By subtracting the weight of basket from the total mass, we calculated the immersed mass $\left(m_{i}\right)$ of each sample. Then, we removed the sample from the wire basket, dried it to a constant mass, dry mass $\left(m_{d}\right)$, in an oven at $110^{\circ} \mathrm{C}$.

\subsubsection{Phase Analysis Using X-Ray Diffraction}

To study the effect of elevated sintering temperature on phase transformation of nano$\mathrm{TiO}_{2}$ ceramics, X-ray diffraction (XRD) patterns were recorded for the nano- $\mathrm{TiO}_{2}$ structures sintered separately at $1200^{\circ} \mathrm{C}, 1300^{\circ} \mathrm{C}, 1400^{\circ} \mathrm{C}, 1500^{\circ} \mathrm{C}$ and $1600^{\circ} \mathrm{C}$ for $3 \mathrm{~h}$, using the same $\mathrm{X}$ ray diffractometer and parameters as above (Model D/MAX-B, Rigaku Co., Tokyo, Japan).

\subsubsection{Microstructural Analysis}

Scanning electron microscopy (SEM) can provide high magnification images of solid materials with a high depth of field. In this study, SEM was used to observe and analyze the microstructure of sintered $\mathrm{TiO}_{2}$ ceramics. Specimens sintered at different sintering temperatures were gold-coated for 1 min using a magnetron sputter coater from Emitech Inc. The gold-coated specimens were observed in a JOEL SEM (Model 6400F, JEOL, Tokyo, Japan). 


\subsubsection{Mechanical Characterization}

In order to determine the mechanical properties of nanostructured $\mathrm{TiO}_{2}$ ceramics sintered at different temperatures, both Vickers hardness test and compression test were conducted. Hardness test was carried out using a Vickers diamond indenter on a hardness tester (Model LV7000, LECO Co., St. Joseph, MI). Sintered ceramic specimens of both nano and commercial $\mathrm{TiO}_{2}$ ceramics were tested and evaluated for their hardness. During the hardness test, a load of $9.8 \mathrm{~N}$ with a loading time of $5 \mathrm{~s}$ was applied to ensure that no crack propagation path was developed. Compressive strength of these ceramics was evaluated in a universal tensile testing machine (under compressive loading) (Model 3369, Instron Co., USA) with a constant crosshead speed of $0.5 \mathrm{~mm} / \mathrm{min}$. 


\section{CHAPTER FOUR: RESULTS}

\subsection{Powder Characterization}

\subsubsection{Differential Scanning Calorimetry / Thermal Gravimetric Analysis}

The as-synthesized $\mathrm{TiO}_{2}$ powder was measured for its thermal properties from room temperature to $900^{\circ} \mathrm{C}$ in air at a heating rate of $6^{\circ} \mathrm{C} / \mathrm{min}$. The results are shown in Figure 11 . Evidently, the weight loss proceeded in stages with increasing temperature, while the most significant weight loss occurred before $400^{\circ} \mathrm{C}$. After $400^{\circ} \mathrm{C}$, the thermogravimetric curve showed a nearly flat characteristic.

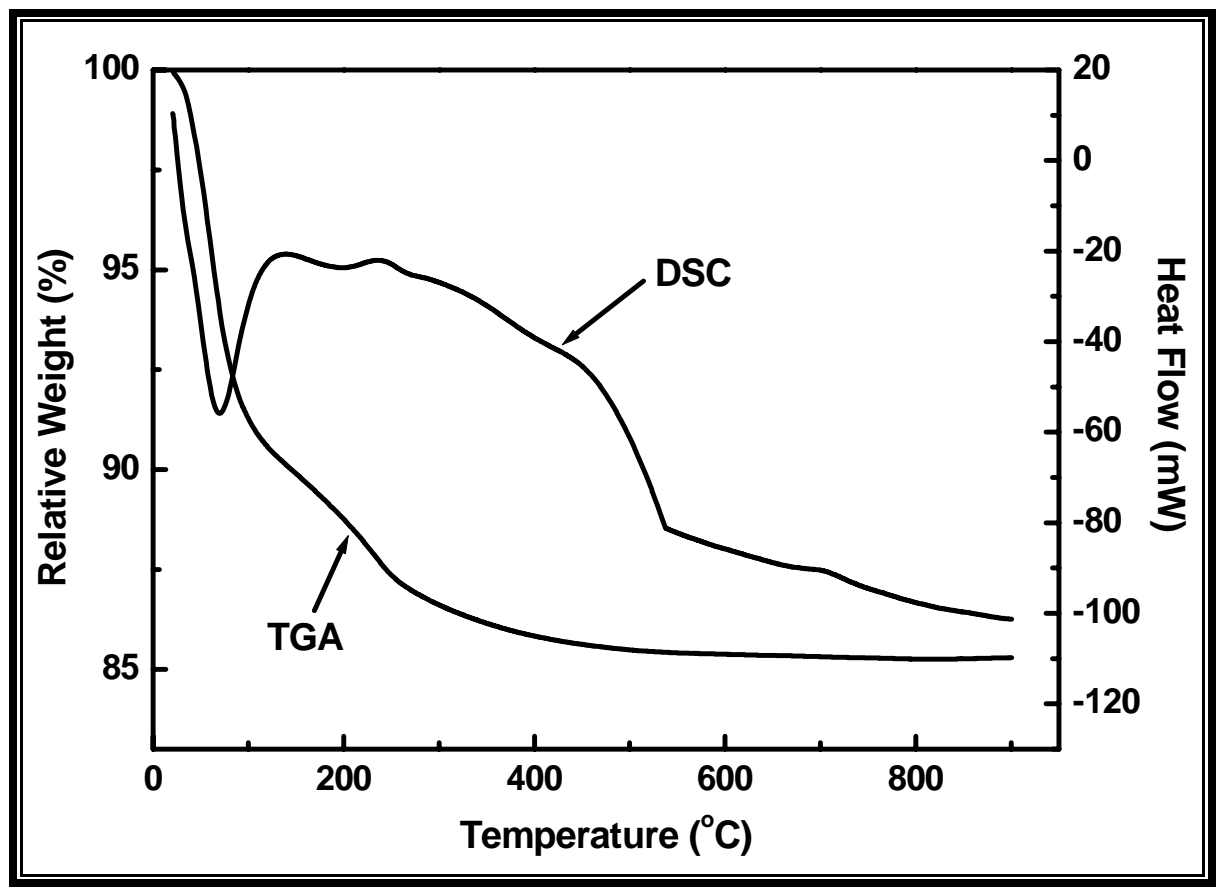

Figure 11. DSC-TGA traces of the as-synthesized $\mathrm{TiO}_{2}$ powders measured at a heating rate of

$6^{\circ} \mathrm{C} / \mathrm{min}$ in air. 
Further calculation showed that, at $400^{\circ} \mathrm{C}$, the weight loss was about $14.2 \%$, while at $900^{\circ} \mathrm{C}$, the total weight loss was about $14.7 \%$. The DSC curve showed a sharp endothermic peak around $100^{\circ} \mathrm{C}$, which was followed by a broad exothermic peak. The broad peak changed to a plateau shape around $520^{\circ} \mathrm{C}$, and continued until around $800^{\circ} \mathrm{C}$.

\subsubsection{Phase Analysis and Crystallite Size Determination}

The XRD patterns for nano- $\mathrm{TiO}_{2}$ and commercial $\mathrm{TiO}_{2}$ powders, calcined at $400^{\circ} \mathrm{C}$ for 3 $\mathrm{h}$, are shown in Figure 12. The presence of anatase and rutile phases of $\mathrm{TiO}_{2}$ was further confirmed by comparing with JCPDS standard files \#21-1272 and \#21-1276, respectively. Peak broadening due to small crystallite size effect can be also clearly seen when comparing diffraction patterns from nano- $\mathrm{TiO}_{2}$ and commercial $\mathrm{TiO}_{2}$ powder. By using Scherrer's formula

(equation 5), at $\lambda=1.5418 \AA, \beta=0.774$ (in radians), $2 \theta=24.92^{\circ}$, the crystallite size of the synthesized $\mathrm{TiO}_{2}$ powder was found to be $10.5 \mathrm{~nm}$. 


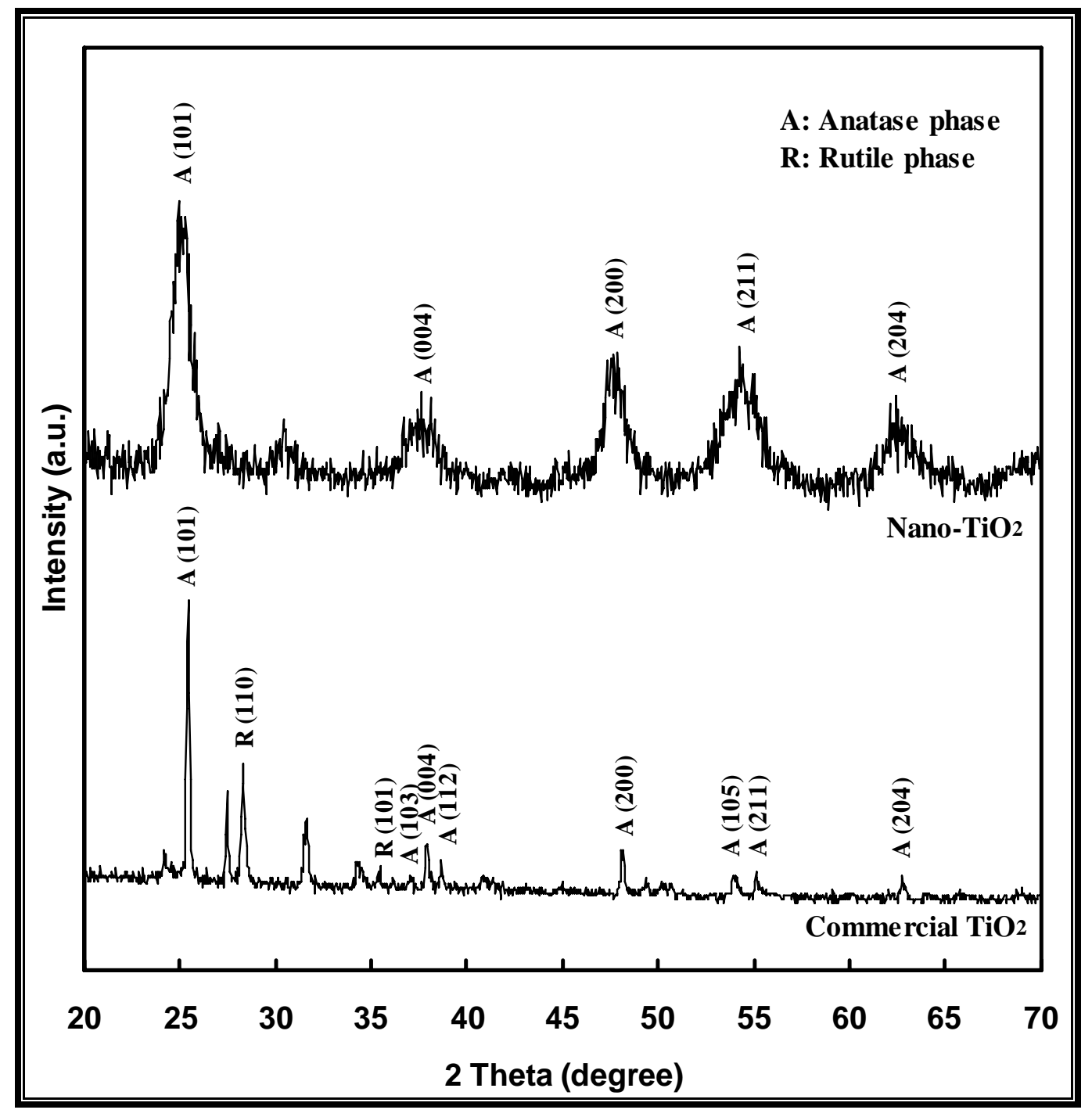

Figure 12. Comparison of XRD patterns of commercial $\mathrm{TiO}_{2}$ and nanocrystalline $\mathrm{TiO}_{2}$ powders calcined at $400^{\circ} \mathrm{C}$ for $3 \mathrm{~h}$. Other unlabeled peaks observed in commercial $\mathrm{TiO}_{2}$ are due to the existing impurities, such as $\mathrm{Mg}$ and $\mathrm{Ca}$.

\subsubsection{High-resolution Transmission Electron Microscopy}

Figure 13 shows the high-resolution TEM image of the as-synthesized $\mathrm{TiO}_{2}$ nanocrystallites calcined at $400^{\circ} \mathrm{C}$, for $3 \mathrm{~h}$. It shows clear lattice fringes, indicating the established 
crystallinity of $\mathrm{TiO}_{2}$ crystallites. Since a crystallite can be defined by studying the orientation of the lattice fringes, one can see the average crystallite size in the synthesized $\mathrm{TiO}_{2}$ powder is about $5 \sim 10 \mathrm{~nm}$ in diameter.

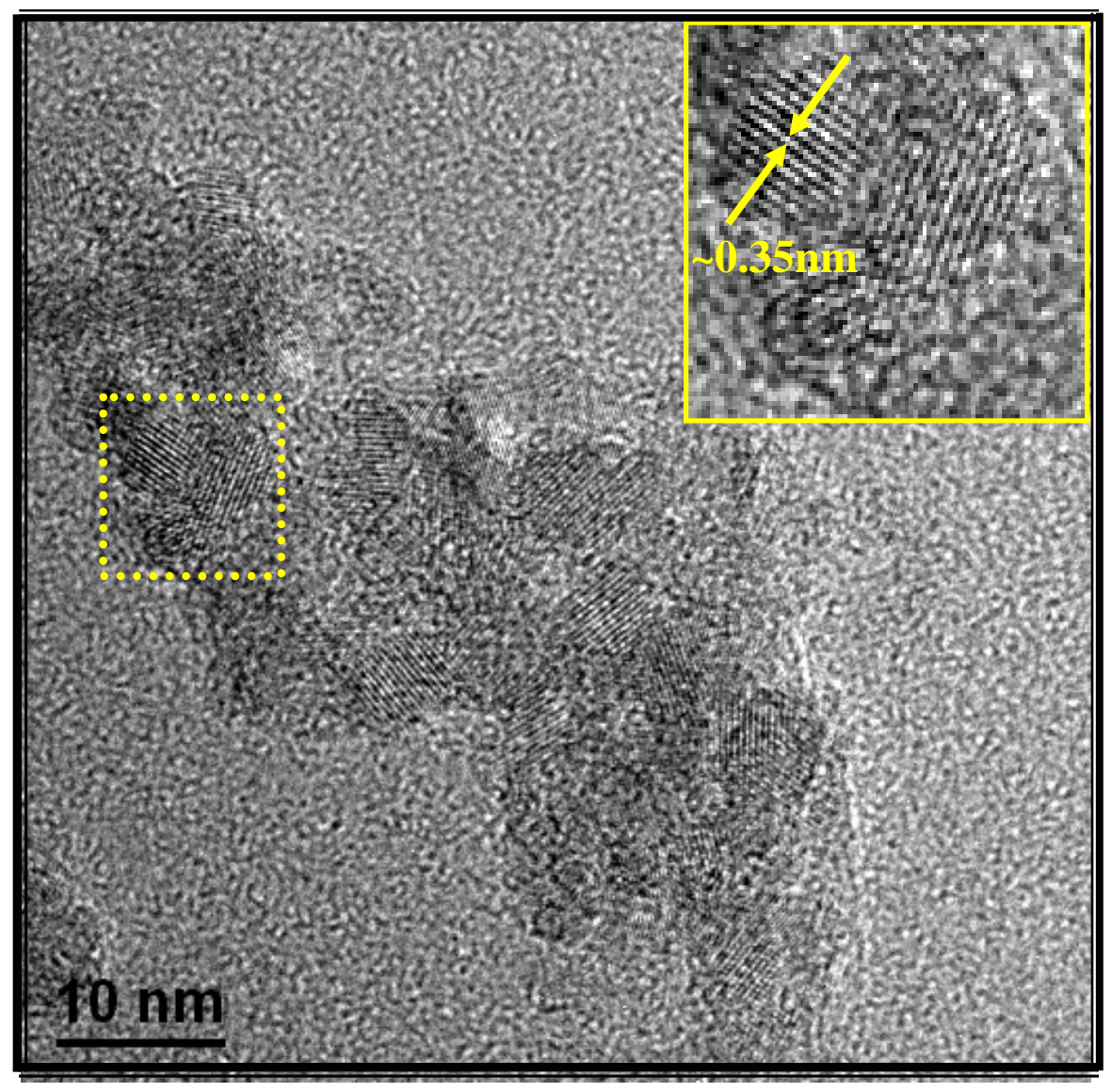

Figure 13. High-resolution TEM image of as-processed nano- $\mathrm{TiO}_{2}$ powder prepared by a Sol-Gel process and calcined at $400^{\circ} \mathrm{C}$ for $3 \mathrm{~h}$. 


\subsubsection{Process of Rutilization}

Since the properties of $\mathrm{TiO}_{2}$ are greatly influenced by rutilization process [79] and the process, on the other hand, depends a lot on the crystallite size. For example, it may take place around $700^{\circ} \mathrm{C}$ for samples with "normal" crystallite sizes and can be seen about $500^{\circ} \mathrm{C}$ for nano $\mathrm{TiO}_{2}$ and $1000^{\circ} \mathrm{C}$ for very coarse $\mathrm{TiO}_{2}$, we also studied the crystallite size-phase contentcalcination temperature relationship by using XRD technique.

The XRD patterns of the synthesized $\mathrm{TiO}_{2}$ nano-powders calcined at $400^{\circ} \mathrm{C}, 600^{\circ} \mathrm{C}$ and $800^{\circ} \mathrm{C}$ are shown in Figure 14, which revealed the presence of anatase and/or rutile phases of $\mathrm{TiO}_{2}$ depending on the calcination temperatures. The phase transformation process can be clearly seen in the patterns: at $400^{\circ} \mathrm{C}$, only anatase phase was presenting; at $600^{\circ} \mathrm{C}$, there evolved a mixture of anatase and rutile phases; while at $800^{\circ} \mathrm{C}$, only rutile phase remained. Also, diffraction peaks became sharper due to coarsening of the crystallites as calcinations temperature went up. By using the Scherrer's formula, the crystallite sizes of anatase and rutile, $D_{\mathrm{a}}$ and $D_{\mathrm{r}}$, were also evaluated from the widths of anatase (101) and rutile (110) reflections. While the $D_{\mathrm{a}}=$ $10.5 \mathrm{~nm}$ at $400^{\circ} \mathrm{C}, D_{\mathrm{a}}=22.6 \mathrm{~nm}$ and $D_{\mathrm{r}}=29.3 \mathrm{~nm}$ at $600^{\circ} \mathrm{C}$, and there was an obvious thermal growth of $\mathrm{TiO}_{2}$ grains. However, even at $800^{\circ} \mathrm{C}$, crystallite size of the synthesized $\mathrm{TiO}_{2}$ was still remained in nano range $\left(D_{\mathrm{r}}=46.2 \mathrm{~nm}\right)$. 


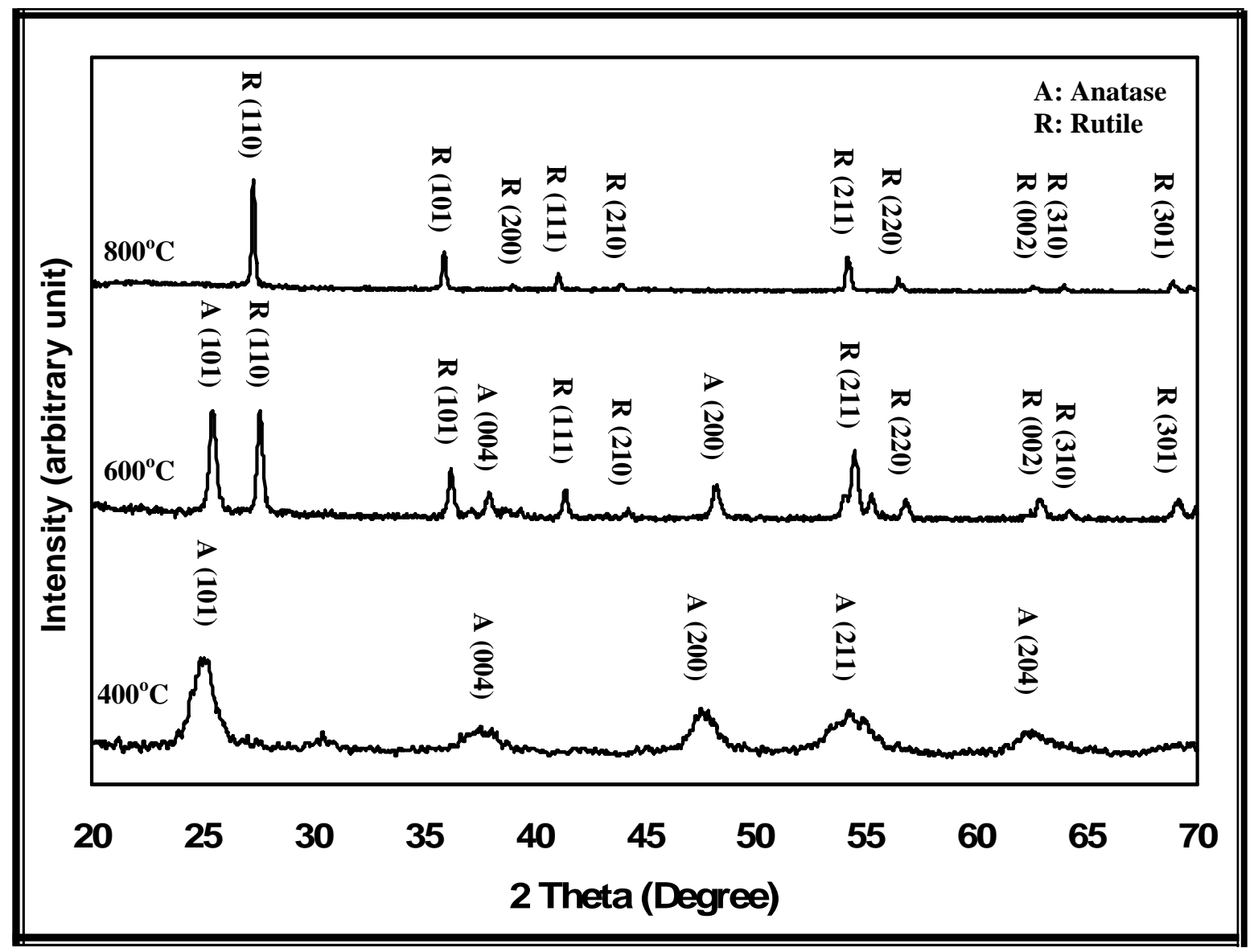

Figure 14. XRD patterns of nanocrystalline $\mathrm{TiO}_{2}$ powders calcined at $400^{\circ} \mathrm{C}, 600^{\circ} \mathrm{C}$ and $800^{\circ} \mathrm{C}$ for $3 \mathrm{~h}$, respectively.

\subsection{Sintering and Densification Studies}

\subsubsection{Density and Porosity Development}

A vivid presentation of sintering effect on the commercial $\mathrm{TiO}_{2}$ and nano- $\mathrm{TiO}_{2}$ ceramics can be seen from Figure 15, which showed the shape changes of the samples after sintering. Bulk density of a material is the ratio of the mass in air to its volume (including the open and closed voids normal to the material) at a stated temperature. The effect of sintering temperature on 
sintered geometric bulk density of commercial $\mathrm{TiO}_{2}$ and nano- $\mathrm{TiO}_{2}$ ceramics (consolidated from powders with nanocrystallite structure) is shown in Figure 16. As one can see from these graphs, for both kinds of $\mathrm{TiO}_{2}$ ceramics, the densification process continued with the elevation of the sintering temperature. For nano- $\mathrm{TiO}_{2}$ ceramics, the density vs. sintering temperature curve began to show a flat trend after reaching $1300^{\circ} \mathrm{C}$. While for the commercial $\mathrm{TiO}_{2}$ ceramics, the flat trend began at around $1400^{\circ} \mathrm{C}$. At all sintering temperatures, the sintered density of nano- $\mathrm{TiO}_{2}$ ceramics was significantly higher than that of commercial $\mathrm{TiO}_{2}$ ceramics.

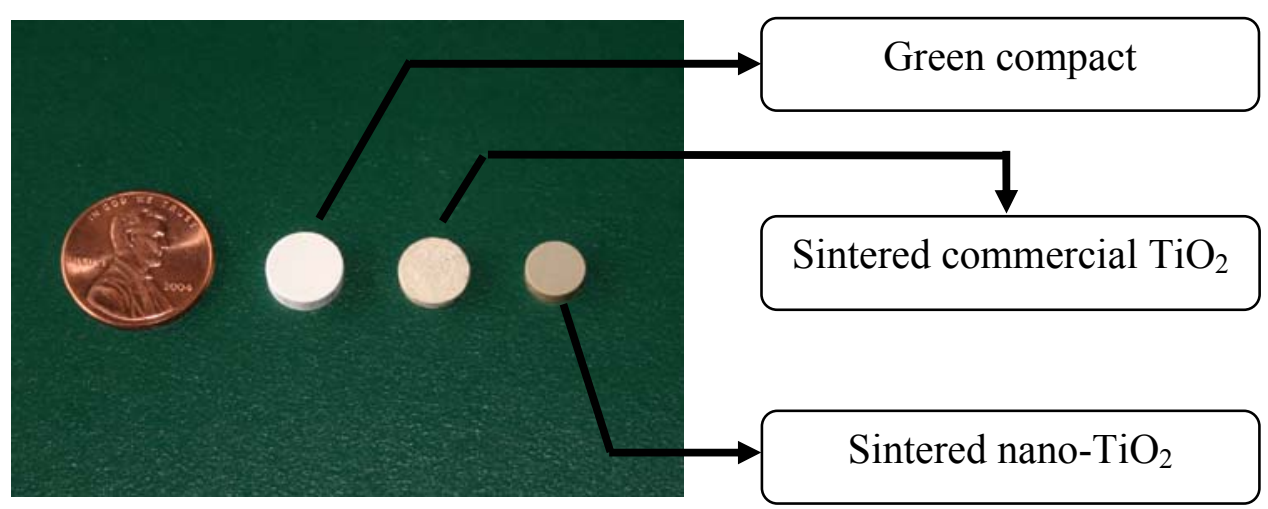

Figure 15. A photograph taken for different $\mathrm{TiO}_{2}$ samples, showing the shape changes after sintering 


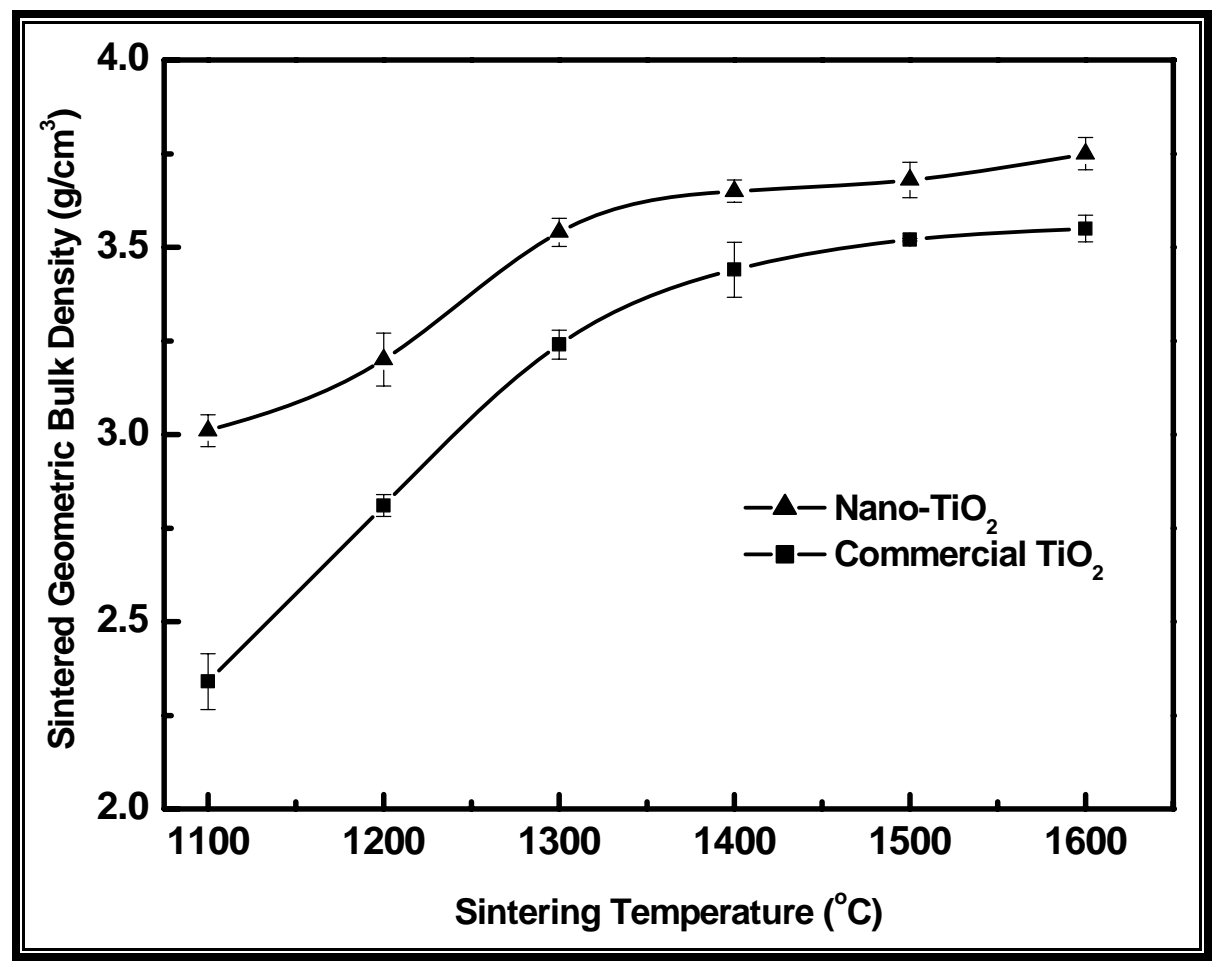

Figure 16. Comparison of sintered density of $\mathrm{TiO}_{2}$ ceramics, consolidated from commercial and synthesized powders, sintered at different temperatures for $3 \mathrm{~h}$ at ambient atmosphere.

Volumetric sintered density, apparent sintered density and apparent porosity of the specimens as a function of sintering temperature is demonstrated in Figure 17. As seen in this figure, both apparent density and volumetric bulk density increased with the increase in the sintering temperature in the range of $1300-1600^{\circ} \mathrm{C}$. However, at all sintering temperatures, $\rho_{\mathrm{a}}$ was always higher than $\rho_{\mathrm{v}}$. While, as this densification process continued, apparent porosity significantly decreased from $18.5 \%$ to $7.0 \%$. 


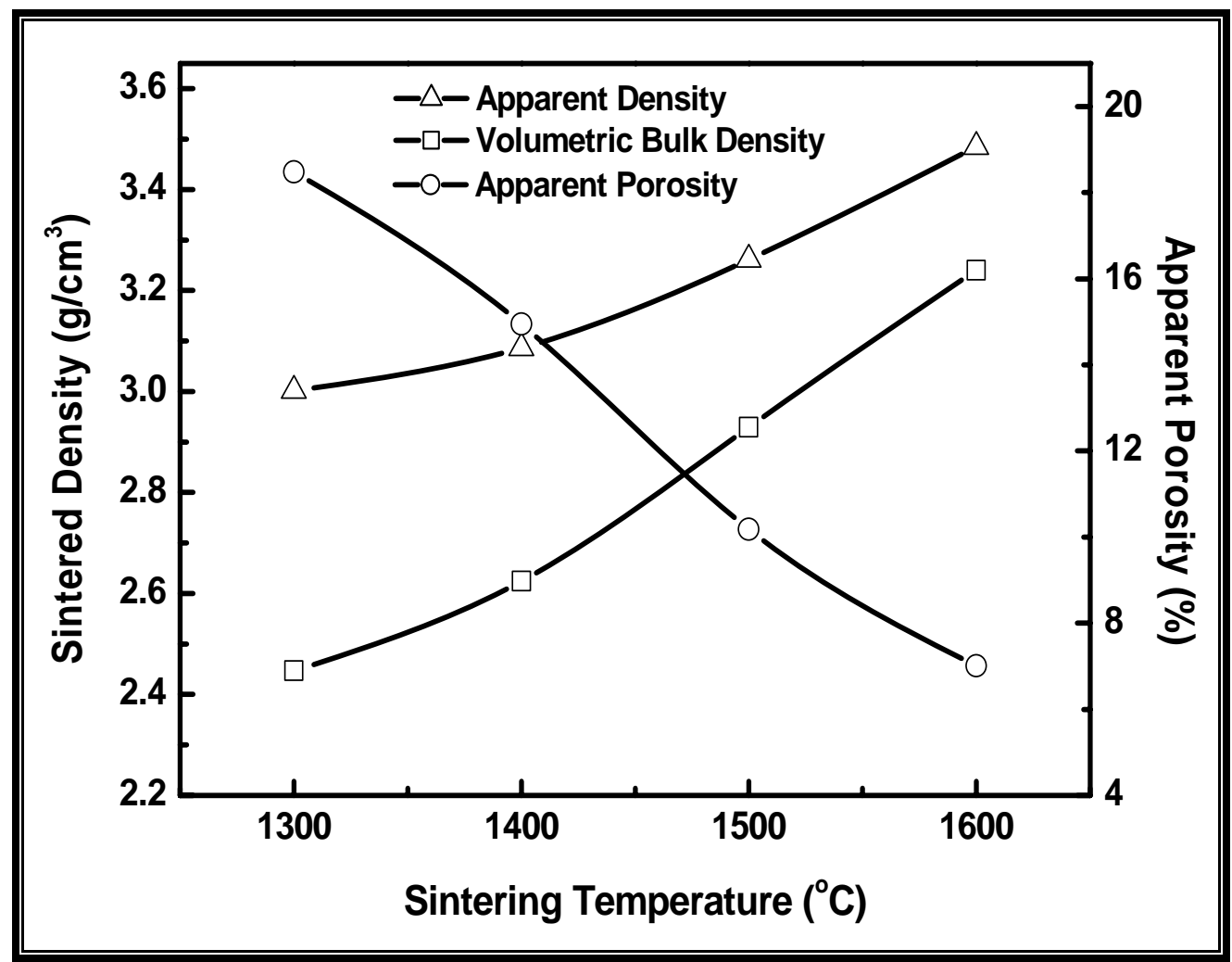

Figure 17. Sintered density and porosity of $\mathrm{TiO}_{2}$ ceramics as a function of sintering temperature.

\subsubsection{Phase Transformation/Evolution Analysis}

Besides recording the phase transformation of nanocrystalline $\mathrm{TiO}_{2}$ in the initial and subsequent stages $\left(400-800^{\circ} \mathrm{C}\right)$, we were also concern about the phase patterns at elevated sintering temperatures, since they might provide us with valuable information to explain the mechanical property difference in $\mathrm{TiO}_{2}$ structures sintered at different temperature. The XRD patterns for $\mathrm{TiO}_{2}$ ceramics sintered in the range of $1200-1600^{\circ} \mathrm{C}$ for $3 \mathrm{~h}$ are shown in Figure 18. It shows that the phase transformation from anatase to rutile had already completed at $1200^{\circ} \mathrm{C}$ and XRD patterns are nearly the same for different sintering temperatures $\left(1200-1600^{\circ} \mathrm{C}\right)$, except 
the intensity and sharpness of the rutile peaks grew with the increase in sintering temperature, indicating an increase in the crystallite size in the sintered structures.

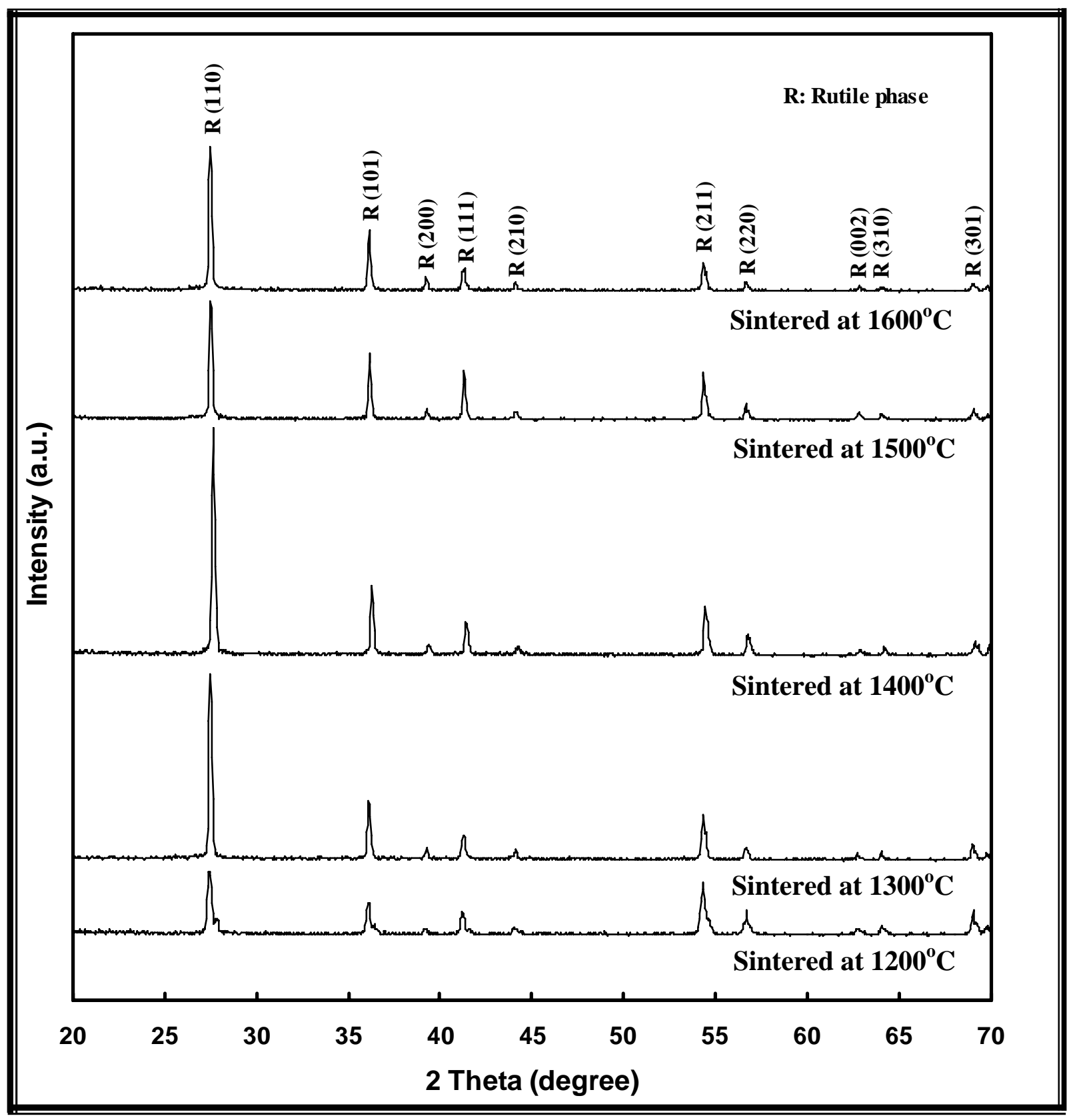

Figure 18. XRD patterns of $\mathrm{TiO}_{2}$ ceramics sintered at in the range of $1200-1600^{\circ} \mathrm{C}$ for $3 \mathrm{~h}$. 


\subsubsection{Microstructural Analysis}

The effects of sintering temperature on the microstructure of the sintered $\mathrm{TiO}_{2}$ ceramics were studied in a JOEL SEM and the obtained SEM micrographs are shown in Figure 19. It was observed that the grain growth continued with the increase in the sintering temperature. Larger crystallite sizes were observed in structures sintered at elevated temperature. Grain boundaries are clearly seen in the SEM micrographs. At $1300^{\circ} \mathrm{C}$, the grain size was around $3.2 \mu \mathrm{m}$; at $1400^{\circ} \mathrm{C}$, the grain size increased to $7 \mu \mathrm{m}$. Larger grain sizes were observed in structures sintered at elevated temperature. At $1600^{\circ} \mathrm{C}$, the grain size had already increased to around $21 \mu \mathrm{m}$. The pore density decreased in this temperature range of $1300-1600^{\circ} \mathrm{C}$, which meant better densification could be achieved. This result is consistent with what we obtained in the densification study. 

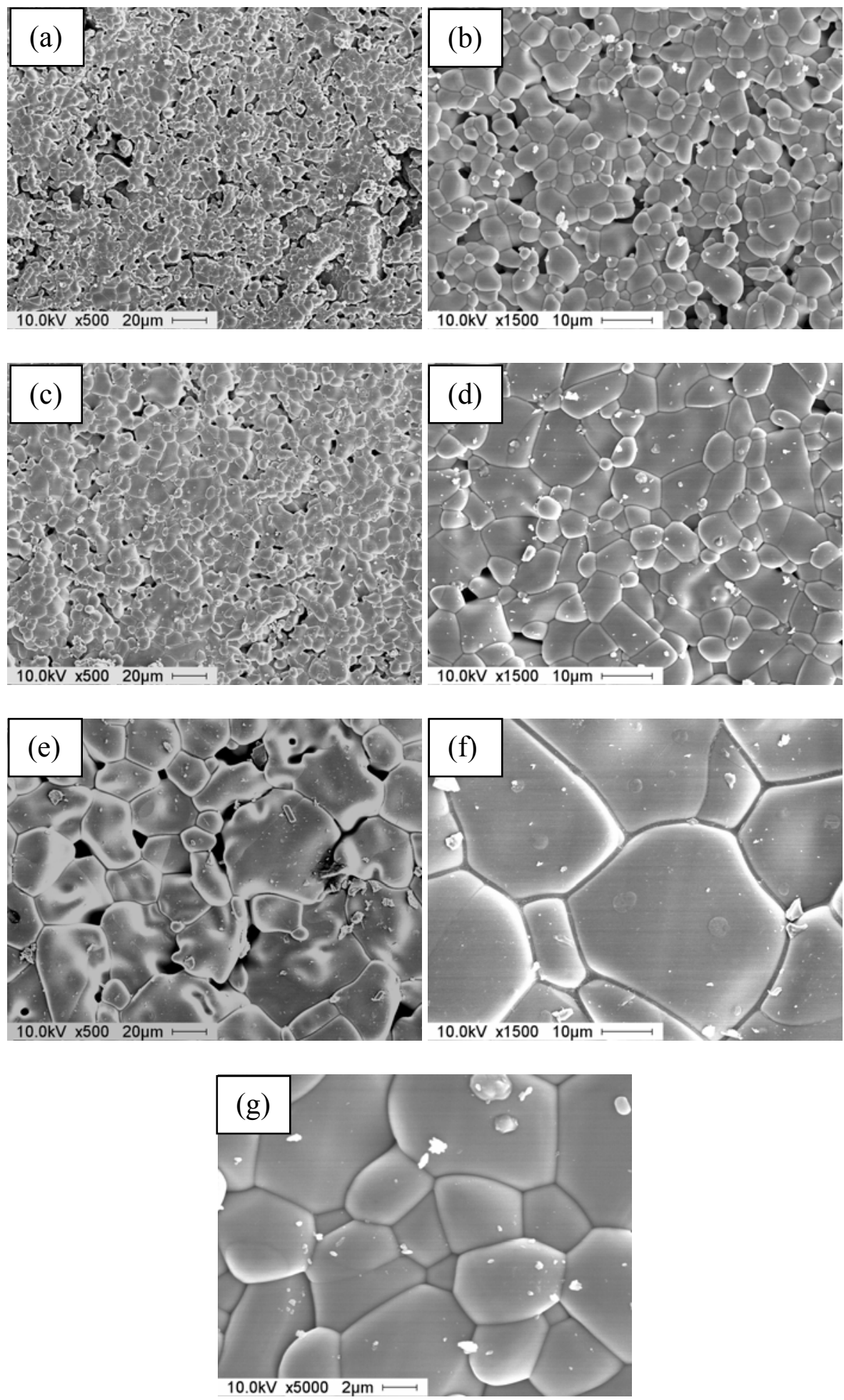

Figure 19. SEM micrographs of $\mathrm{TiO}_{2}$ ceramics sintered at (a) and (b) $1300^{\circ} \mathrm{C}$; (c), (d) and (g) $1400^{\circ} \mathrm{C}$, (e) and (f) $1600^{\circ} \mathrm{C}$ for $3 \mathrm{~h}$ at ambient atmosphere. 


\subsection{Mechanical Characterization}

\subsubsection{Vickers Hardness Testing}

Even though we measured the sintered densities of all ceramics in the sintering temperature range of $1100-1600^{\circ} \mathrm{C}$, we found that the commercial $\mathrm{TiO}_{2}$ ceramics did not seem to be sintered well: the surface was uneven which made it impossible to find the Vickers indentation marks to measure their hardness. On the contrary, the surface of all nano- $\mathrm{TiO}_{2}$ ceramics looked smooth and dense. For that reason, mechanical properties of commercial $\mathrm{TiO}_{2}$ structures were not measured. Again, since nano- $\mathrm{TiO}_{2}$ ceramics sintered at $1100^{\circ} \mathrm{C}$ and $1200^{\circ} \mathrm{C}$ showed relatively low sintered density, they were also not selected for mechanical characterization.

Figure 20 gives Vickers hardness and compression strength results recorded for nano$\mathrm{TiO}_{2}$ ceramics sintered at the range of $1300-1600^{\circ} \mathrm{C}$ in which the ceramics showed good densification result. It can be observed from the figure that the Vickers hardness increased with the elevation of the sintering temperatures, and a maximum average hardness value of 471.8 $\pm 30.3 \mathrm{HV}$ was obtained for specimens sintered at $1600^{\circ} \mathrm{C}$. 


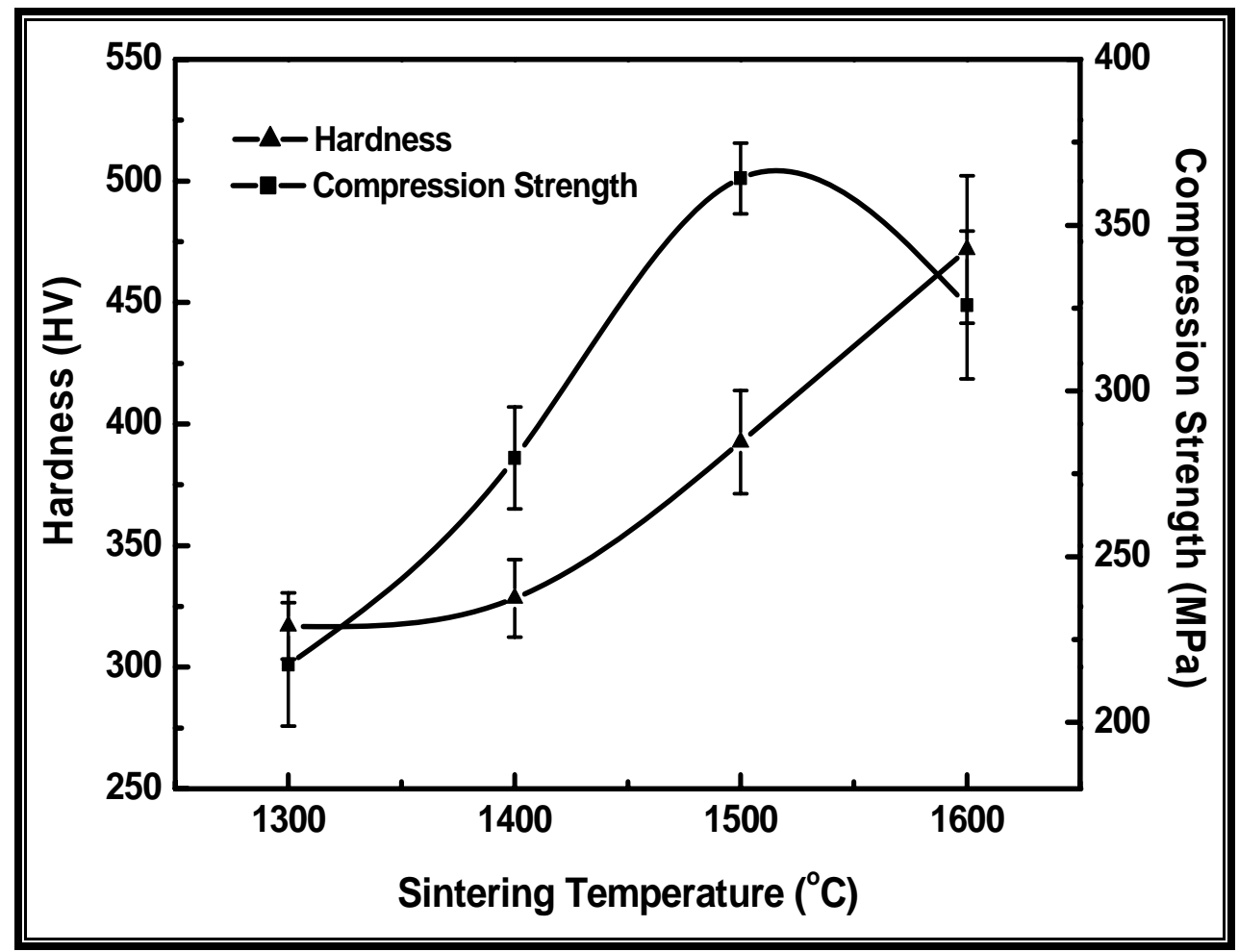

Figure 20. Variation of Vickers hardness and compression strength of $\mathrm{TiO}_{2}$ ceramics as a function of sintering temperature.

\subsubsection{Compression Testing}

As we can see from Figure 20, the compression strength showed a little different trend from what we observed in the hardness testing: while the compression strength continued to increase with the sintering temperature until $1500^{\circ} \mathrm{C}$, where a maximum value of $364.1 \pm 10.7$ $\mathrm{MPa}$ was achieved, the compression strength decreased as we continue to increase the sintering temperature. Figure 21 is a typical load-displacement curve of the $\mathrm{TiO}_{2}$ ceramics sintered at $1500^{\circ} \mathrm{C}$. 


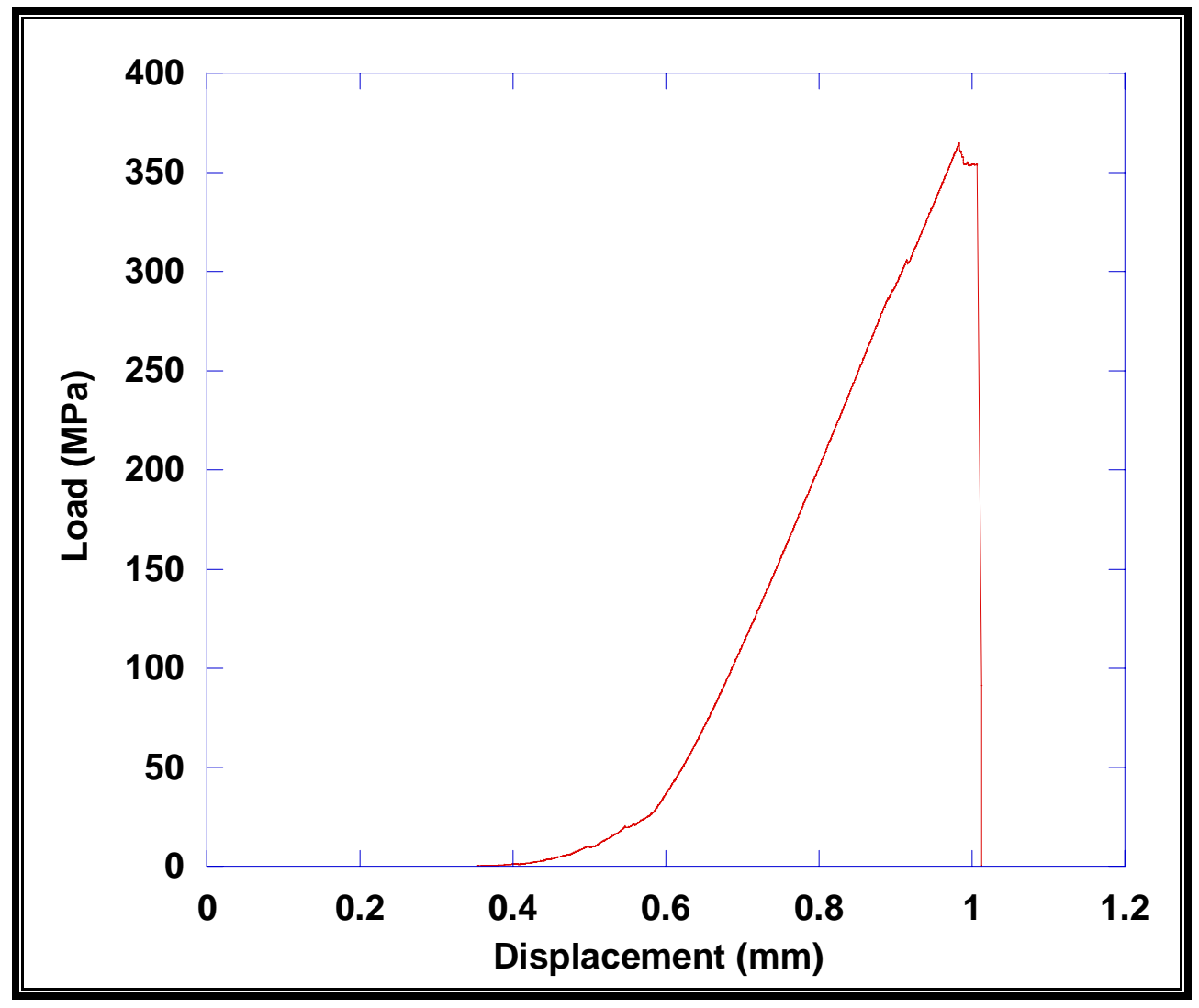

Figure 21. A typical load-displacement curve of $\mathrm{TiO}_{2}$ ceramics sintered at $1500^{\circ} \mathrm{C}$

\subsection{Rietveld Refinement of X-ray Diffraction Data}

Figure 22 shows the results of Rietveld refinement of the X-ray diffraction data for the $\mathrm{TiO}_{2}$ powder calcined at $400^{\circ} \mathrm{C}$ for $3 \mathrm{~h}$. As we can see from the dialogue box, the reduced CHI ** 2 value was 1.427 and the convergence was achieved, which meant quality of the fit was good. The lattice parameters for the as-synthesized nano- $\mathrm{TiO}_{2}$ powder were calculated as $\mathrm{a}=\mathrm{b}=0.3793 \mathrm{~nm}, \mathrm{c}=0.9502 \mathrm{~nm}, \alpha=\beta=\gamma=90^{\circ}$, which were quite reasonable when comparing with the literature values for anatase phase. 


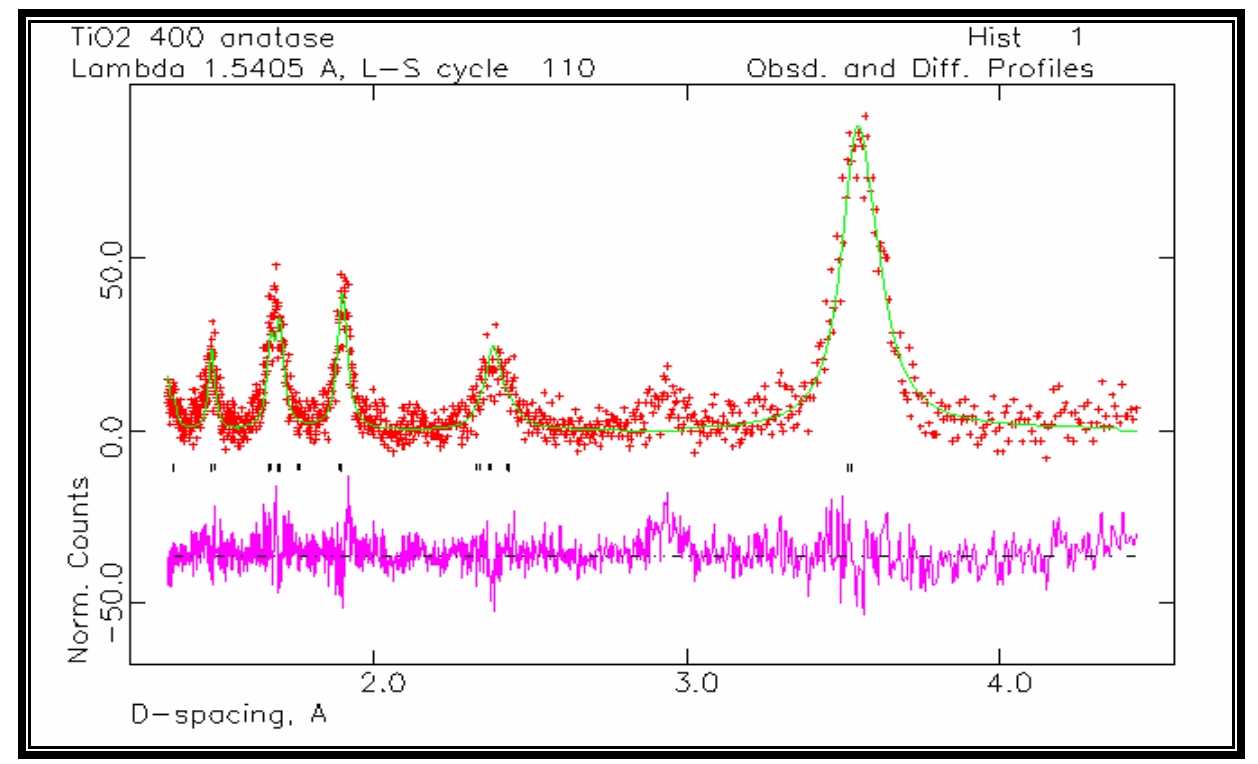

(a)

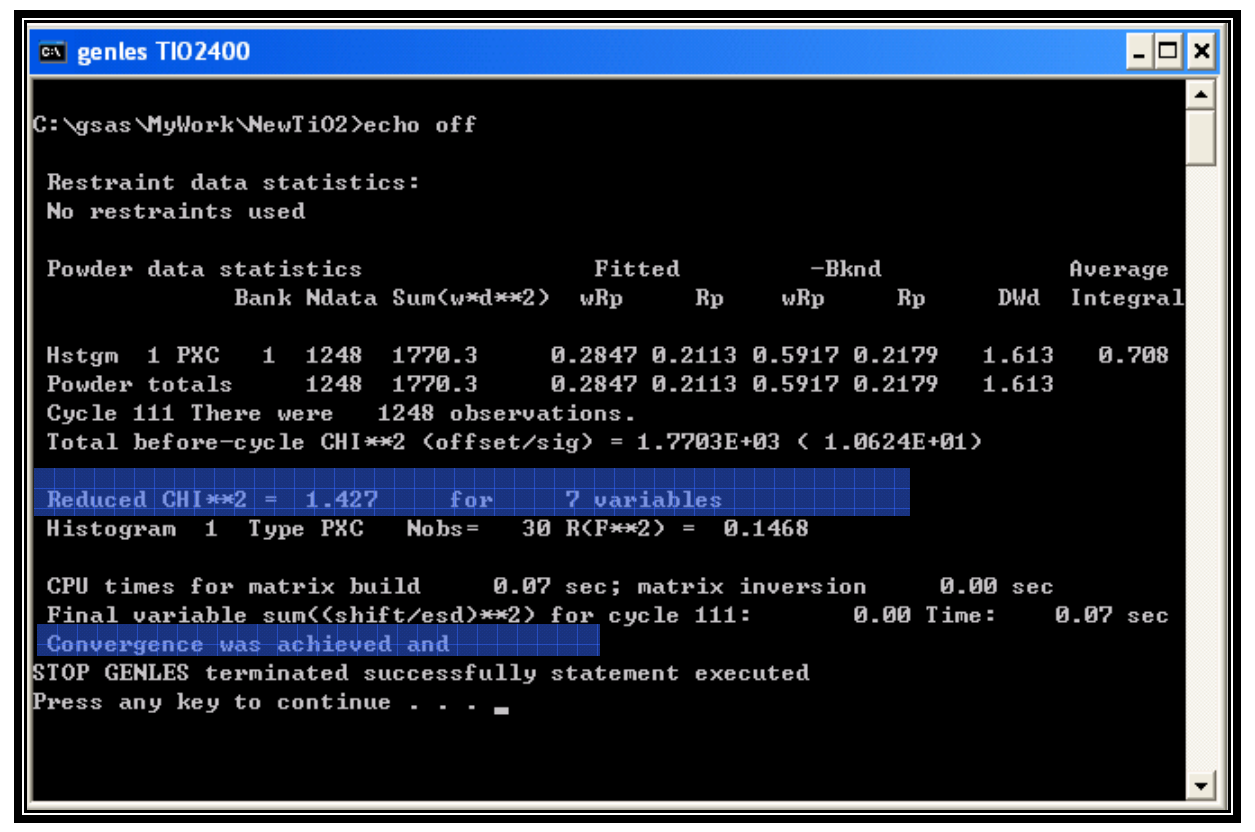

(b)

Figure 22. (a) Rietveld refinement results of the nano- $\mathrm{TiO}_{2}$ powder calcined at $400^{\circ} \mathrm{C}$ for $3 \mathrm{~h}$ (b)

The dialogue box showed the reduced $\mathrm{CHI} * * 2$ value was 1.427 and the convergence was achieved 


\section{CHAPTER FIVE: DISCUSSION}

\subsection{Phase Evolution and Transformation in Calcined Nanocrystalline $\mathrm{TiO}_{2}$ Powders}

In the DSC-TGA result (Figure 11) of the as-prepared amorphous powders, the sharp endothermic peaks in the DSC curve at approximately $50^{\circ} \mathrm{C}$ and $120^{\circ} \mathrm{C}$, which corresponded to a large weight loss in TGA curve, can be associated with vaporization of water and the oxidative elimination of organic residue. While the weight loss nearly stabilized after $400^{\circ} \mathrm{C}$, we presumed that the additional small amount of weight loss above $400^{\circ} \mathrm{C}$ was probably caused by a residual decomposition product that formed a sheath over the $\mathrm{TiO}_{2}$ particles [80]. The broad exothermic peak continued until around $800^{\circ} \mathrm{C}$, which corresponded to the anatase-rutile transformation finishing temperature, since it was an exothermic process which was confirmed by JANAF thermochemical data [81]. Finally, we selected $400^{\circ} \mathrm{C}$ as the optimum calcination temperature, high enough to achieve crystallization, and optimum to reduce the thermal growth of the crystallites and maintain nanoscale features in the calcined powder.

As we can see in XRD pattern of the nanocrystalline $\mathrm{TiO}_{2}$ powders calcined at $400^{\circ} \mathrm{C}$ (Figure 12), it is clear that a peak was recorded at $2 \theta$ value of $24.882^{\circ}$, which corresponded to crystalline anatase phase of $\mathrm{TiO}_{2}$. And no phase transformation from anatase to rutile occurred at this calcination temperature. While as a comparison, in commercial $\mathrm{TiO}_{2}$ powder, the rutile phase was observed.

The average crystallite size from HR-TEM in the synthesized $\mathrm{TiO}_{2}$ powder is about $5 \sim 10$ $\mathrm{nm}$ by observation (Figure 13), which is in good agreement with the above calculation from XRD analysis. Also, we know that the lattice images are interference patterns between the direct 
beam and diffracted beams in HR-TEM and the spacing of a set of fringes is proportional to the lattice spacing, when the corresponding lattice planes meet the Bragg condition. So when we chose an area and magnified for further observation (as shown in the inset of Figure 13), the distance between lattice fringes was found to be $0.35 \mathrm{~nm}$, which perfectly matched with the lattice spacing of (101) plane in the anatase phase of $\mathrm{TiO}_{2}$ [82].

As what we discussed before, no phase transformation from anatase to rutile occurred at calcination temperature of $400^{\circ} \mathrm{C}$. When we increased the temperature to $600^{\circ} \mathrm{C}$, considerable amount of rutile phase appeared. An approximation of the weight fraction of rutile phase $\left(W_{\mathrm{R}}\right)$ at one temperature can be calculated from equation (10) [83], where $A_{\mathrm{A}}$ represents the integrated intensity of the anatase (101) peak, and $A_{R}$ the integrated intensity of rutile (110) peak. After calculation, we knew that around $46.6 \%$ of rutile phase existed. As we raised the temperature to $800^{\circ} \mathrm{C}$, the rutile phase increased its percentage rapidly to about $100 \%$, and the anatase to rutile phase transformation had already completed and no anatase phase was left. This result was in good corresponding to the DSC-TGA result, in which the broad exothermic peak continued until around $800^{\circ} \mathrm{C}$. The results of relative rutile phase percentage and crystallite sizes as a function of calcination temperature were plotted in Figure 23.

$$
W_{R}=\frac{A_{R}}{0.884 A_{A}+A_{R}}
$$

Synthesis of nanoscale $\mathrm{TiO}_{2}$ powder has been accomplished by many researchers. Compared to some of the research work in recent years on the synthesis of $\mathrm{TiO}_{2}$ nano powder 
$[18,19,21,76]$ (which can be referred to table 3), our process used a simple sol-gel technique, which can be easily controlled and reproduced. The particle size was relatively small, and can still keep the nano features even when we elevated the calcination temperature to $800^{\circ} \mathrm{C}$, for $3 \mathrm{~h}$. In addition, for those applications where pure anatase phase is of importance, such as photocatalysts [84], solar cells [85] and electrochromic devices [86] applications, the assynthesized nano-sized $\mathrm{TiO}_{2}$ powder, obtained in this work, will be very useful.

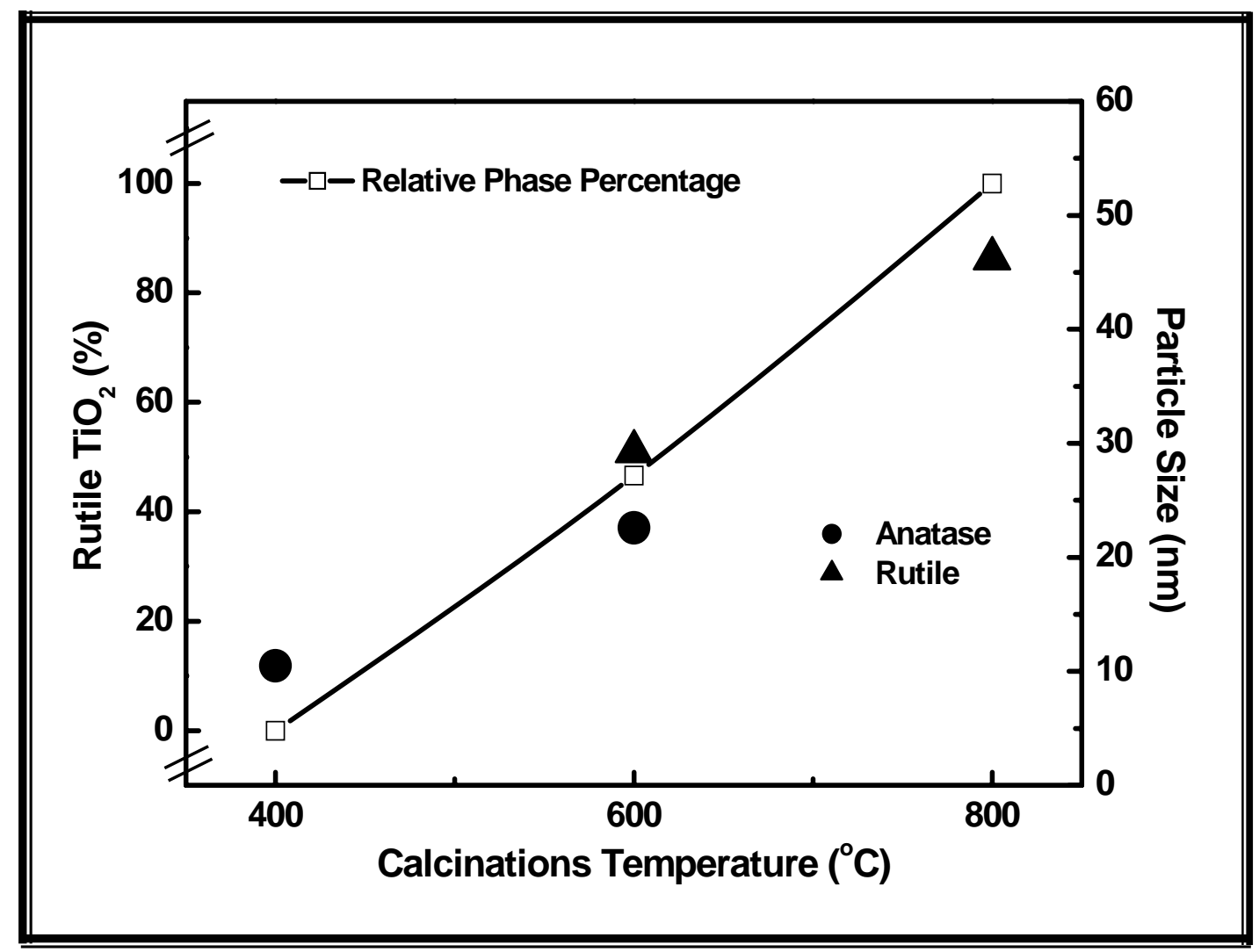

Figure 23. Rutile percentage and crystallite size determined by XRD for the nanocrystalline $\mathrm{TiO}_{2}$ powders after calcination at $400^{\circ} \mathrm{C}, 600^{\circ} \mathrm{C}$ and $800^{\circ} \mathrm{C}$ for $3 \mathrm{~h}$. 
Table 3. Summary of recent research work in synthesis of nano- $\mathrm{TiO}_{2}$

\begin{tabular}{|c|c|c|c|}
\hline Year & Investigator & Research Topic & Preparation Methods and Results \\
\hline 2001 & $\begin{array}{l}\text { Zilong Tang } \\
\text { et al. [19] }\end{array}$ & $\begin{array}{l}\text { Synthesis of } \\
\text { nano rutile } \mathrm{TiO}_{2} \\
\text { powder at low } \\
\text { temperature }\end{array}$ & $\begin{array}{l}\text { - Sol-gel method, using } \mathrm{Ti}\left(\mathrm{OC}_{4} \mathrm{H}_{9}\right)_{4} \text { and } \\
\mathrm{HNO}_{3} \text {; } \\
\text { - Mean particle size is about } 50 \mathrm{~nm} \text { after } \\
\text { calcination at } 600^{\circ} \mathrm{C} \text {, in rutile phase. }\end{array}$ \\
\hline 2002 & $\begin{array}{l}\text { Baorang Li } \\
\text { et al. [76] }\end{array}$ & $\begin{array}{l}\text { Preparation and } \\
\text { characterization } \\
\text { of nano- } \mathrm{TiO}_{2} \\
\text { powder }\end{array}$ & $\begin{array}{l}\text { - Sol-gel method, using tetra-n-butyl-titanate } \\
\text { and deionized water; } \\
\text { - Mean particle size is about } 10 \mathrm{~nm} \text { after } \\
\text { calcination at } 400^{\circ} \mathrm{C} \text {, but increased to } 40 \mathrm{~nm} \\
\text { after calcination at } 600^{\circ} \mathrm{C} \text {. }\end{array}$ \\
\hline 2002 & $\begin{array}{l}\text { Jimmy C. } \\
\text { Yu et al. } \\
{[21]}\end{array}$ & $\begin{array}{l}\text { Photocatalytic } \\
\text { activity of } \\
\text { nano-sized } \mathrm{TiO}_{2} \\
\text { powders }\end{array}$ & $\begin{array}{l}\text { - Sol-gel method, using TTIP and EtOH/ } \mathrm{H}_{2} \mathrm{O} \\
\text { solution; } \\
\text { - Obtained anatase }(75.1 \%) \text { and brookite } \\
(24.9 \%) \text { phases at } 400^{\circ} \mathrm{C} \text {, and the particle } \\
\text { size were } 7.9 \mathrm{~nm} \text { and } 7.4 \mathrm{~nm} \text {, respectively. }\end{array}$ \\
\hline 2004 & $\begin{array}{l}\text { Ana M. Ruiz } \\
\text { et al. [18] }\end{array}$ & $\begin{array}{l}\text { Microstructure } \\
\text { control of } \\
\text { thermally stable } \\
\mathrm{TiO}_{2} \text { obtained } \\
\text { by } \\
\text { hydrothermal } \\
\text { process }\end{array}$ & $\begin{array}{l}\text { - Sol-gel method; } \\
\text { - Hydrothermally treated } \mathrm{TiO}_{2} \text { nanoparticles } \\
\text { at pH } 3 \text { were } 13 \text { and } 34 \mathrm{~nm} \text { in average } \\
\text { diameter after calcination at } 600 \text { and } 800^{\circ} \mathrm{C} \text {; } \\
\text { - Hydrothermally treated } \mathrm{TiO}_{2} \text { nanoparticles } \\
\text { at pH } 2 \text { were } 11 \text { and } 26 \mathrm{~nm}_{\text {in }} \text { average } \\
\text { diameter after calcination at } 600 \text { and } 800^{\circ} \mathrm{C} \text {. }\end{array}$ \\
\hline 2006 & $\begin{array}{l}\text { Shipeng Qiu } \\
\text { et al. [87] }\end{array}$ & $\begin{array}{l}\text { Synthesis, } \\
\text { processing and } \\
\text { characterization } \\
\text { of nano- } \mathrm{TiO}_{2}\end{array}$ & $\begin{array}{l}\text { - Sol-gel method, using TTIP, isopropanol } \\
\text { and } \mathrm{H}_{2} \mathrm{O} \text {; } \\
\text { - } 5 \sim 10 \mathrm{~nm} \text { in diameter after calcination at } \\
400^{\circ} \mathrm{C} \text {, in pure anatase phase; } \\
\text { - Anatase }(53.4 \%) \text { and rutile }(46.6 \%) \text { phases } \\
\text { after calcination at } 600^{\circ} \mathrm{C} \text {, and the particle } \\
\text { size were } 22.6 \mathrm{~nm} \text { and } 29.3 \mathrm{~nm}, \\
\text { respectively; } \\
46.2 \mathrm{~nm} \text { in diameter after calcination at } \\
800^{\circ} \mathrm{C} \text {, in pure rutile phase. }\end{array}$ \\
\hline
\end{tabular}




\subsection{Sintering and Densification of $\mathrm{TiO}_{2}$ Ceramics}

The sintering process is driven by the tendency to reduce the excessively large surface area per unit volume. The extra energy of a surface with a radius of curvature, $R$, may be calculated as a stress $(\sigma)$ in a Laplace equation (11):

$$
\sigma=\gamma / \mathrm{R}
$$

where $\gamma$ is the surface energy. Thermodynamically, nanopowders are highly unstable, and this sintering stress may reach very high values. While, from kinetics point of view, significantly enhanced kinetics are also expected for processes that display a direct grain size dependence. For sintering, this dependence may be illustrated using the equation (12) for the densification rate ( $d \mathrm{~L} / \mathrm{L} d \mathrm{t})$ developed by Johnson and co-workers for all stages of sintering: [88]

$$
-\frac{d L}{L d t}=\frac{\not \Omega}{k T}\left(\frac{\delta D_{b} \Gamma_{b}}{d^{4}}+\frac{D_{v} \Gamma_{v}}{d^{3}}\right)
$$

where $\gamma$ is the surface energy, $\Omega$ is the atomic volume, $\delta$ is the grain boundary width, $\mathrm{D}_{b}$ and $\mathrm{D}_{v}$ are the grain boundary and bulk diffusivities, $\Gamma_{b}$ and $\Gamma_{v}$ are functions of density, $k T$ has the usual meaning, and $d$ is the grain size. From this equation, it is seen that decreasing grain size by three

orders of magnitude (e.g., from $\mu \mathrm{m}$ to $\mathrm{nm}$ ) could enhance sintering rates by up to 12 orders of magnitude. As a result, sintering of nanopowders may be accomplished at significantly lower temperatures and shorter period of time compared with conventional powders. 
In our research of the densification process, we also found that when the sintering temperature was at $1100^{\circ} \mathrm{C}(3 \mathrm{~h})$, the volume shrinkage of nano- $\mathrm{TiO}_{2}$ ceramics was about $42.0 \%$, while no noticeable shrinkage (just around 9.3\%) was found in the commercial $\mathrm{TiO}_{2}$ ceramics. This also proved the above established fact that, the densification process will begin at a relatively lower temperature for ceramics made from nanopowders compared with those made from powders with conventional size. Also, at all sintering temperatures, the sintered density of nano- $\mathrm{TiO}_{2}$ ceramics was significantly higher than that of commercial $\mathrm{TiO}_{2}$ ceramics, which once again proved that nano- $\mathrm{TiO}_{2}$ exhibits better densification compared to conventional counterpart.

As we can see from Figure 17, at all sintering temperatures, $\rho_{\mathrm{a}}$ was always higher than $\rho_{\mathrm{v}}$. The reason for this trend is that $\rho_{\mathrm{v}}$ quantifies solid material, open and closed pores; on the other hand, $\rho_{\mathrm{a}}$ quantifies only the volume of solid material and closed pores.

\subsection{Mechanical Properties of Sintered $\mathrm{TiO}_{2}$ Ceramics}

Hardness value is observed to be well correlated with sintered density (From Figure 17 and Figure 20), that is, when the sintered density is low, the corresponding hardness value of specimens is also low. For example, specimens sintered at $1300^{\circ} \mathrm{C}$ had an average geometric bulk density of $3.54 \mathrm{~g} / \mathrm{cm}^{3}$ and their average hardness was only $316.9 \pm 13.6 \mathrm{HV}$. Whereas, a maximum average hardness value of $471.8 \pm 30.3 \mathrm{HV}$ was obtained for specimens sintered at $1600^{\circ} \mathrm{C}$, which has also shown the highest geometric bulk sintered density of $3.75 \mathrm{~g} / \mathrm{cm}^{3}$.

However, related explanation accounting for the changing of the compression strength with sintering temperatures can be better explained with the help of microstructural analysis (Figure 19). Evidently, in the case of low sintering temperature at $1300^{\circ} \mathrm{C}$, the porosity is quite 
high and most pores are interconnected. For the specimens sintered at $1400^{\circ} \mathrm{C}$ and $1600^{\circ} \mathrm{C}$, continuous grain boundary networks have been formed. Most of the pores are present at triple junctions and grain boundaries. In light of this microstructural information, the decrease in porosity at $1400^{\circ} \mathrm{C}$ and higher temperatures is possibly due to the bridging of fine crystallites and formation of closed pores. There is no apparent secondary phases present in the grain interior or at the grain boundaries. And we also know from the XRD analysis that only the rutile phase is present within this range of sintering temperature. Below $1500^{\circ} \mathrm{C}$, the removal of pores during the densification process played a significant role in increasing the compressive strength, since specimens had smaller grain-sizes and the distribution of grain size was relatively homogenous and uniform compared to those sintered at higher temperatures, particularly at $1600^{\circ} \mathrm{C}$. Again, with the increase in the sintering temperature, it was expected that the material would achieve better densification at the expense of grain growth. This effect was especially significant at $1600^{\circ} \mathrm{C}$. Large, irregular-shaped grains were observed (as can be seen in Figure 19 (f)), which dramatically decreased the compression strength of the ceramics. 


\section{CHAPTER SIX: CONCLUSIONS}

In this paper, we describe an easily controlled Sol-Gel process of synthesizing nanocrystalline $\mathrm{TiO}_{2}$ powder. Calcined powders and further sintered structures are characterized for their phases, microstructure, and mechanical properties. Findings from this research are listed below:

1. Nanocrystalline $\mathrm{TiO}_{2}$ powder can be successfully synthesized through a simple Sol-Gel process of hydrolyzing titanium tetraisopropoxide (TTIP) in a mixture of isopropanol and deionized water;

2. $400^{\circ} \mathrm{C}$ was selected as an optimum calcination temperature from DSC-TGA results. While it was high enough to achieve crystallization in the powders, at the same time, the temperature selected can minimize the thermal growth of the crystallites and maintain nanoscale features in the calcined powder;

3. After calcination at $400^{\circ} \mathrm{C}(3 \mathrm{~h}), \mathrm{XRD}$ results showed that the synthesized nano- $\mathrm{TiO}_{2}$ powder was mainly in single anatase phase. Crystallite size was first calculated through XRD, then confirmed by HR-TEM, and found to be around $5 \sim 10 \mathrm{~nm}$;

4. While pure anatase existed at calcination temperature of $400^{\circ} \mathrm{C}$, considerable amount of rutile phase had already formed at $600^{\circ} \mathrm{C}$, and the phase transformation from anatase to rutile totally completed at $800^{\circ} \mathrm{C}$. The above rutilization process was clearly recorded from XRD data, and was in good corresponding to the DSC-TGA result, in which the broad exothermic peak continued until around $800^{\circ} \mathrm{C}$; 
5. Results of the sintered $\mathrm{TiO}_{2}$ ceramics $\left(1100^{\circ} \mathrm{C}-1600^{\circ} \mathrm{C}\right)$ showed that, the densification process continued with the increase in sintering temperature and the highest geometric bulk sintered density of $3.75 \mathrm{~g} / \mathrm{cm}^{3}$ was achieved at $1600^{\circ} \mathrm{C}$, while the apparent porosity significantly decreased from $18.5 \%$ to $7.0 \%$ in this temperature range, the trend of which can be clearly observed in SEM micrographs;

6. The hardness of the $\mathrm{TiO}_{2}$ ceramics increased with the increase in sintering temperature and the maximum hardness of $471.8 \pm 30.3 \mathrm{HV}$ was obtained at $1600^{\circ} \mathrm{C}$. Compression strength increased until $1500^{\circ} \mathrm{C}$ and the maximum value of $364.1 \pm 10.7 \mathrm{MPa}$ was achieved; after which a gradual decrease was observed. With the increase in the sintering temperature, it was expected that the material would achieve better densification at the expense of grain growth. As a result, though the sintered density at $1600^{\circ} \mathrm{C}$ was the highest, large and irregular-shaped grains formed at this temperature would lead to the decrease in the compression strength. 


\section{CHAPTER SEVEN: FUTURE DIRECTIONS AND SUGGESTIONS}

The mechanical properties are known to be sensitive to the grain size; therefore, the development of the fine grain and nanostructured $\mathrm{TiO}_{2}$ is of current scientific interested. As we can see from the SEM micrographs of $\mathrm{TiO}_{2}$ ceramics sintered at $1300^{\circ} \mathrm{C}, 1400^{\circ} \mathrm{C}$ and $1600^{\circ} \mathrm{C}$ for $3 \mathrm{~h}$ at ambient atmosphere, the grain size is in micron range, which means that the nanofeatures are lost during sintering. Actually, many techniques have been used to control grain growth in order to produce dense materials with nanometer-scale structure, for example, hot pressing, spark plasma sintering, transformation sintering, etc. Here, I would like to recommend to use a promising but relatively simple method - two-step sintering [89]. This was first demonstrated for

cubic $\mathrm{Y}_{2} \mathrm{O}_{3}$ (melting point, $2439^{\circ} \mathrm{C}$ ), which was fully densified at the second-step temperature of $1000^{\circ} \mathrm{C}$ with a final grain size of $60 \mathrm{~nm}$. The schematic sintering schedule with a prolonged, lowtemperature hold following the initial sintering at a higher temperature is shown in Figure 26. The most remarkable feature of this method is that there is continued densification in the second step but the final-stage grain growth is completely suppressed, so nanocrystalline ceramics can be obtained using this method. Until now, the details of this method as applied to $\mathrm{Y}_{2} \mathrm{O}_{3}, \mathrm{BaTiO}_{3}$ and NiCuZn ferrite base have been reported.

The densification process for conventional powders is well known, both theoretically and practically. However, the densification of nanopowders poses significant additional challenges. Powder agglomeration, high reactivity and, therefore, contamination, grain coarsening, and ultimate loss of the nanofeatures, and inability to fabricate large and dense parts are among the main problems. 


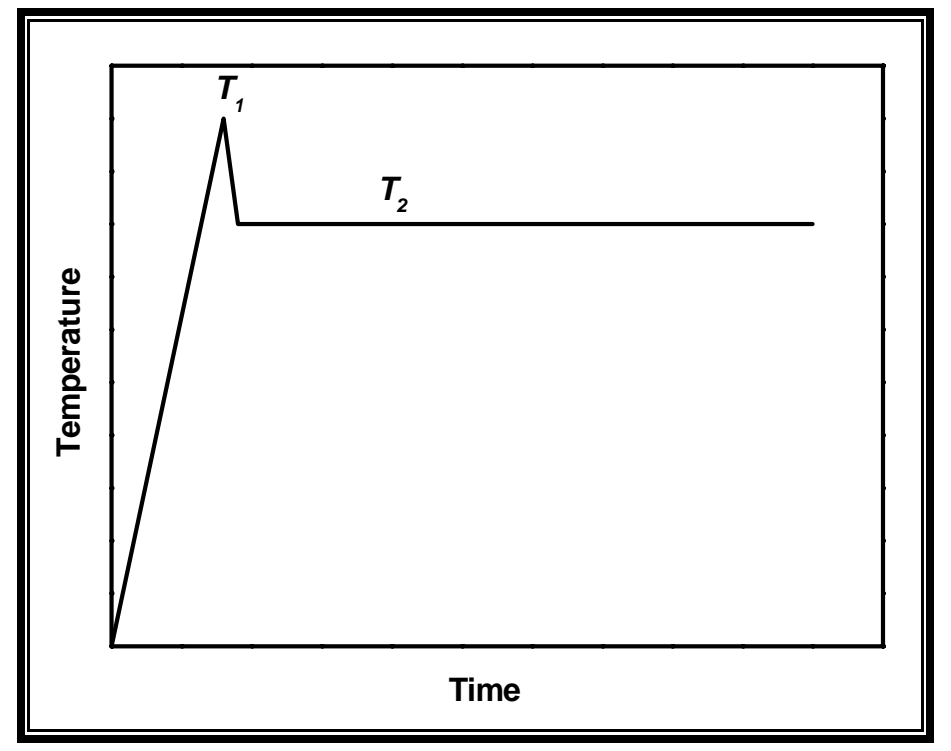

Figure 26. Schematic temperature schedule for two-step sintering

Also, another problem encountered in fabricating nanograined ceramics is powder compaction before sintering. The ideal green body should be a uniformly dense arrangement of powders without flaws or defects. However, the major drawback of the simple method of uniaxial pressing used in this study is that, it can result in density and stress gradients throughout the green body. Alternate ways to improve the powder compaction and green density of pellet structures can be used to get a better control of achieving nanocrystalline ceramics. 


\section{LIST OF REFERENCES}

[1] U. Diebold, Surf. Sci. Rep., 48, (2003) 53.

[2] C. O. Park, S. A. Akbar and W. Weppner, J. Mater. Sci., 38, (2003) 4639.

[3] K. Zakrzewska, Vacuum, 74, (2004) 335.

[4] O. Carp, C. L. Huisman and A. Reller, Prog. Solid State Chem., 32, (2004) 33.

[5] I. Tsyganov, M. F. Maitz and E. Wieser, Appl. Surf. Sci., 235, (2004) 156.

[6] R. Paily, A. D. Gupta, N. D. Gupta, P. Bhattacharya, P. Misra, T. Ganguli, L. M. Kukreja, A. K. Balamurugan, S. Rajagopalan and A. K. Tyagi, Appl. Surf. Sci., 187, (2002) 297.

[7] O. K. Tan, W. Cao, Y. Hu and W. Zhu, Ceramics International, 30, (2004) 1127.

[8] Y. Z. Li, N. H. Lee, E. G. Lee, J. S. Song and S. J. Kim, Chem. Phys. Lett., 389, (2004) 124.

[9] C. H. Lee, H. S. Choi, C. H. Lee and H. J. Kim, Surf. Coat. Technol., 173, (2003) 192.

[10] H. Gleiter, Prog. Mater. Sci., 33, (1989) 223.

[11] A. C. Jones and P. R. Chalker, J. Phys. D: Appl. Phys., 36, (2003) R53.

[12] K. L. Choy, Prog. Mater. Sci., (2003) 57.

[13] J. A. Agllon, A. Figueras, S. Garelik, L. Spirkova, J. Durand and L. Cot, J. Mater. Sci. Lett. 18, (1999) 1319.

[14] M. K. Akhtar, Y. Xiong and S. E. Pratsinis, AICHE J., 37, (1991) 1561.

[15]H. D. Jang and J. K. Jeong, Aerosol Sci. Technol., 23, (1997) 553.

[16]H. Shimakawa, F. Sakamoto and Y. Tsuchida, Ceram. Powder Sci., 4, (1993) 115.

[17] E. Haro-Poniakowski, R. Rodr' guez-Talavera, M. de la Cruz Heredia, O. Cano-Corona, and R. Arroyo-Murillo, J. Mater. Res., 9, (1994) 2102. 
[18] A. M. Ruiz, G. Sakai, A. Cornet, K. Shimanoe, J. R. Morante and N. Yamazoe, Sens. Actuators., B 103, (2004) 312.

[19] Z. L. Tang, J. Y. Zhang, Z. Cheng and Z. T. Zhang, Mater. Chem. Phys., 77, (2002) 314.

[20] S. Qourzal, A. Assabbane and Y. Ait-Ichou, J. Photochem. Photobiol. A: Chem., 163, (2004) 317.

[21] J. C. Yu, J. G. Yu, L. Z. Zhang and W. K. Ho, J. Photochem. Photobiol. A: Chem., 148, (2002) 263.

[22] J. M. Lackner, W. Waldhauser, R. Ebner, B. Major and T. Schoberl, Surface and Coatings Tech., 180-181, (2004) 585.

[23] A. K. Jamting, J. M. Bell, M. V. Swain, L.S. Wielunski and R. Clissold, Thin Solid Films, 332, (1998) 189.

[24] A. O. Olofinjana, J. M. Bell and A. K. Jamting, Wear, 241, (2000) 174.

[25] M. A. Barteau, J. Vac. Sci. Technol., A11, (1993) 2162.

[26] L. S. Dubrovinsky, N.A. Dubrovinskaia, V. Swamy, et al., Nature, 410, (2001) 653.

[27] G. V. Samsonov, The Oxide Handbook, IFI/Plenum Press, New York, 1982.

[28] A. Heller, Acc. Chem. Res., 14, (1981) 154.

[29] S. N. Frank, A.J. Bard, J. Am. Chem. Soc., 99, (1977) 303.

[30] S. N. Frank, A.J. Bard, J. Phys. Chem., 81, (1977) 1484.

[31] D. F. Ollis and H. Al-Ekabi, Elsevier, Amsterdam, 1993.

[32] M. A. Fox and M. T. Dulay, Chem. Rev., 93, (1993) 341.

[33] A. Fujishima, K. Hashimoto, T. Watanabe, BKC, Tokyo, 1999.

[34] A. Heller, Acc. Chem. Res., 28, (1995) 503. 
[35] H. Honda, A. Ishizaki, R. Soma, et al., J. Illum. Eng. Soc., Winter, (1998) 42.

[36] Y. Ohko, K. Hashimoto and A. Fujishima, J. Phys. Chem. A, 101, (1997) 8057.

[37] K. Ishibashi, A. Fujishima, T. Watanabe, et al., J. Photochem. Photobiol. A: Chem., 134, 139.

[38] A. Fujishima, T. N. Rao and D. A. Tryk, J. Photochem. Photobiol. C: Photochem. Rev., 1 (2000) 1 .

[39] I. Sopyan, S. Marasawa, K. Hashimoto, et al., Chem. Lett., (1994) 723.

[40] H. Matsubara, M. Takasa, S. Koyama, et al. Chem. Lett., (1995) 767.

[41] S. Matsushita, T. Miwa and A. Fujishima, Chem. Lett., (1996) 925.

[42] K. Kobayakawa, C. Sato, Y. Sato, et al. J. Photochem. Photobiol. A: Chem., 118, (1998) 65.

[43] R. Wang, K. Hashimoto, A. Fujishima, et al., Nature, 388, (1997) 431.

[44] N. Sakai, R. Wang, A. Fujishima, et al., Langmuir , 14, (1998) 5918.

[45] A. Nakajima, A. Fujishima, K. Hashimoto, et al., Adv. Mater., 11, (1999) 1365.

[46] R. Wang, K. Hashimoto, A. Fujishima, et al., Adv. Mater., 10, (1998) 135.

[47] P. K. Dutta, A. Ginwalla, B. Hogg, et al., J. Phys. Chem., 103, (1999) 4412.

[48] Y. Xu, K. Yao, X. Zhou, et al., Sens. Actuators B, 13-14, (1993) 492.

[49] U. Kirner, K. D. Schierbaum, B. Leibold, et al., Sens. Actuators B, 1, (1990) 103.

[50] C. Xu, J. Tamaki, N. Miura and N. Yamazor, Sens. Actuators B, 3, (1991) 147.

[51] A. Takami, Ceram. Bull., 67 (12), (1988) 1956.

[52] Rajnish K. Sharma, M. C. Bhatnagar and G. L. Sharma, Sens. Actuators B, 45, (1997) 209.

[53] J.G. Fagan and V.R.W. Amarakoon, Am. Ceram. Soc. Bull., 72, (1993) 119.

[54] K. Katayama, K. Hasegawa, T. Takahashi, et al., Sens. Actuators, 24, (1990) 55. 
[55]H. Yagi and M. Nakata, J. Ceram. Soc. Jpn., 100, (1992) 152.

[56] Y. Shimizu, H. Okada and H. Arai, J. Am. Ceram. Soc., 72, (1989) 436.

[57] Rao, C. N. R., Muller, A. and Cheetham, A. K. Eds., Chemistry of nanomaterials, WileyVCH, Weinheim, 2004.

[58] Koch, C. C., Nanostructured materials processing, properties and applications. William Andrew Publishing: New York, 2002.

[59] Gleiter, H., Acta Materialia, 48(1), (2000) 1.

[60] Seal, S. and Baraton, M. I., Mrs Bulletin, 29(1), (2004) 9.

[61] Groza, J. R., Nanosintering Nanostructured Materials, 12(5-8), (1999) 987.

[62] Seal, S. S., Synthesis, functionalization and surface treatment of nanoparticles. American Scienific Publishers: California, 2002.

[63] Averback, R. S., Hofler, H. J., and Tao, R., Mater. Sci. Eng. A, 166, (1993) 169.

[64] Mayo, M. J., Hague, D. C., and Chen, D. J., Mater. Sci. Eng. A, 166, (1993) 145.

[65] Hague, D. C. and Mayo, M. J., Nanostr. Mater., 3, (1993) 61.

[66] Uchic, M., Hofler, H. J., Flick, et al, Scr. Metall. Mater., 26, (1992) 791.

[67] C. Schuh, T. G. Nieh and T. Yamasaki, Scr. Mater., 46, (2002) 735.

[68] C. Schuh, T. G. Nieh and T. Yamasaki, Acta Mater., 51, (2003) 431.

[69] D. H. Jeong, U. Erb, K. T. Aust, and G. Palumbo, Scr. Mater., 48, (2003) 1067.

[70] H. M. Rietveld, J. Appl. Cryst., 2, (1969) 65.

[71] H. M. Rietveld, Acta Crystallogr., 20, (1966) 508.

[72] Report No. LAUR 8-748, Los Alamos National Laboratory, A. C. Larson and R. B. VonDreele, Los Alamos, NM, 1986. 
[73] R. B. VonDreele, J. Appl. Cryst., 30, (1997) 517.

[74] H. J. Bunge, Texture analysis in materials science, Butterworth-Heinemann, London, 1982.

[75] General Structure Analysis System (GSAS), A.C. Larson and R.B. Von Dreele, Los Alamos National Laboratory Report LAUR 86-748, 2004.

[76] B. R. Li, X. H. Wang, M. Y. Yan and L. T. Li, Mater. Chem. Phy., 78, (2002) 184.

[77] C. Suryanarayana and M. G. Norton, X-Ray Diffraction: A Practical Approach. Plenum Press: New York, 1998.

[78] M. M. Akiyoshi, A. P. Da Silva and M. G. Da Silva, Am. Ceram. Soc. Bull., 81, (2002) 39.

[79] D. Huguenin and T. Chopin, Dyes and Pigments, 37, (1998) 129.

[80] D. C. Hague and M. J. Mayo, J. Am. Ceram. Soc., 77, (1994) 1957.

[81]D. R. Stall, "JANAF Thermochemical Tables," Joint Army-Navy-Air Force-ARPA -NASA Thermochemical Working Group, 1996.

[82] N. N. Dinh, N. Th. T. Oanh, P. D. Long, M. C. Bernard and A. Hugot-Le Goff, Thin Solid Films, 423, (2003) 70.

[83] A. A. Gribb and J. F. Banfield, Am. Mineral, 82, (1997) 717.

[84] C. H. Kwon, J. H. Kim, I. S. Jung, H. Shin and K. H. Yoon, Ceram. Inter., 29, (2003) 851.

[85] K. V. Baiju, C. P. Sibu, K. Rajesh, P. K. Pillai, P. Mukundan, K.G. K. Warrier and W. Wunderlich, Mater. Chem. Phys., 90, (2005) 123.

[86] B. O’'regan and M. Gratzel, Nature, 353, (1991) 737.

[87] S. Qiu and S. J. Kalita, Mater. Sci. Eng. A, 435-436, (2006) 327.

[88] Hansen, J. D., Rusin, R. P., Teng, M. H. and Johnson, D. L., J. Am. Ceram. Soc., 75, (1992) 1129. 
[89] Chen, I. W. and Wang, X. H., Nature, 404, (2000) 168. 